\title{
COVID-19 and Ontario's Long-Term Care Homes
}

Nathan M. Stall, $\mathrm{MD}^{1-4}$; Kevin A. Brown, MSc, PhD ${ }^{5,6}$; Antonina Maltsev, $\mathrm{BCom}^{6}$; Aaron Jones, $\mathrm{MSc}, \mathrm{PhD}^{7}$;

Andrew P. Costa, $\mathrm{PhD}^{7-9}$; Vanessa Allen, $\mathrm{MD}^{5,10}$; Adalsteinn D. Brown, DPhil ${ }^{6,11}$; Gerald A. Evans, $\mathrm{MD}^{12}$;

David N. Fisman, MD, $\mathrm{MPH}^{3,6}$; Jennie Johnstone, $\mathrm{MD}, \mathrm{PhD}^{10,13}$;

Peter Jüni, MD, FESC ${ }^{3,4}$; Kamil Malikov, MD, MSc, MBA CPA, $\mathrm{CMA}^{14}$; Allison McGeer, $\mathrm{MD}^{10}$; Paula A. Rochon, MD, $\mathrm{MPH}^{2,3,4,15}$;

Beate Sander, RN, MBA, MEcDev, PhD ${ }^{5,6,16}$; Brian Schwartz, MD, $\mathrm{MSc}^{5,6}$; Samir K. Sinha, MD, DPhil ${ }^{1,3,4,17}$; Kevin Smith, DPhil ${ }^{4,16}$; Ashleigh R. Tuite, PhD, MPH, MSc ${ }^{6}$; Michael P. Hillmer MSc, $\mathrm{PhD}^{4,14}$

${ }^{1}$ Division of General Internal Medicine and Geriatrics, Sinai Health System and the University Health Network, Toronto, Canada

${ }^{2}$ Women's College Research Institute, Women's College Hospital, Toronto, Canada

${ }^{3}$ Department of Medicine, University of Toronto, Toronto, Canada

${ }^{4}$ Institute of Health Policy, Management and Evaluation, University of Toronto, Toronto, Canada

${ }^{5}$ Public Health Ontario, Toronto, Canada

${ }^{6}$ Dalla Lana School of Public Health, University of Toronto, Canada

${ }^{7}$ Department of Health Research Methods, Evidence, and Impact, McMaster University, Hamilton, Canada

${ }^{8}$ Schlegel Chair in Clinical Epidemiology and Aging, McMaster University, Hamilton, Ontario, Canada

${ }^{9}$ Centre for Integrated Care, St. Joseph's Health System, Hamilton, Ontario, Canada

${ }^{10}$ Department of Laboratory Medicine and Pathobiology, University of Toronto, Toronto, Canada

${ }^{11}$ Ontario Health, Toronto, Canada

${ }^{12}$ Department of Medicine, Queens University, Kingston, Canada

${ }^{13}$ Department of Infection Prevention and Control, Sinai Health, Toronto, Canada

${ }^{14}$ Capacity Planning and Analytics Division, Ontario Ministry of Health, Toronto, Canada

${ }^{15}$ ICES, Toronto, Canada

${ }^{16}$ University Health Network, Toronto, Canada

${ }^{17}$ National Institute on Ageing, Ryerson University, Toronto, Canada 
Corresponding author: Nathan M. Stall MD, FRCPC

Division of General Internal Medicine and Geriatrics

Mount Sinai Hospital

Suite 475 - 600 University Avenue

Toronto ON M5G 2C4

Phone: (416) 586-4800 ext. 7856

Fax: (416) 586-5113

Email: nathan.stall@sinaihealth.ca

\section{Abstract}

Ontario long-term care (LTC) home residents have experienced disproportionately high morbidity and mortality, both from COVID-19 and from the conditions associated with the COVID-19 pandemic. As of July 10, 2021, a total of 3,975 LTC home residents have died of COVID-19, totaling $43.0 \%$ of all 9,245 COVID-19 deaths in Ontario.

The most important risk factors for whether a LTC home will experience an outbreak is the daily incidence of SARS-CoV-2 infections in the communities surrounding the home and the occurrence of staff infections. The most important risk factors for the magnitude of an outbreak and the number of resulting resident deaths are older design, chain ownership, and crowding.

Many Ontario LTC home residents have experienced severe and potentially irreversible physical, cognitive, psychological, and functional declines as a result of precautionary public health interventions imposed on homes, such as limiting access to general visitors and essential caregivers, resident absences, and group activities. There has also been an increase in the prescribing of psychoactive drugs to Ontario LTC residents.

The accumulating evidence on COVID-19 in Ontario's LTC homes has been leveraged in several ways to support public health inter- 
ventions and policy during the pandemic. Several further measures could be effective in preventing COVID-19 outbreaks, hospitalizations, and deaths in Ontario's LTC homes. This includes improving staffing, minimizing LTC worker infection, decrowding LTC homes, enhanced infection prevention and control (IPAC) measures, a more balanced and nuanced approach to public health measures, and additional strategies to promote COVID-19 vaccine acceptance amongst residents and staff.

Keywords: SARS-CoV-2, Nursing Home, Congregate Care, Geriatric Medicine, Infection Prevention and Control

\section{COVID-19 y los hogares de cuidados a largo plazo de Ontario}

\section{RESUMEN}

Los residentes en el hogar de cuidados a largo plazo de Ontario (LTC) han experimentado una morbilidad y mortalidad desproporcionadamente altas, tanto por COVID-19 como por las condiciones asociadas con la pandemia de COVID-19. Hasta el 10 de julio de 2021, un total de 3.975 residentes de hogares de LTC habían muerto de COVID-19, lo que totaliza el $43.0 \%$ de las 9.245 muertes por COVID-19 en Ontario.

Los factores de riesgo más importantes para que un hogar de LTC experimente un brote es la incidencia diaria de infecciones por SARS$\mathrm{CoV}-2$ en las comunidades que rodean el hogar y la aparición de infecciones del personal. Los factores de riesgo más importantes para la magnitud de un brote y el número de muertes de residentes resultantes son el diseño antiguo, la propiedad de la cadena y el hacinamiento.

Muchos residentes de hogares de Ontario LTC han experimentado disminuciones físicas, cognitivas, psicológicas y funcionales graves y potencialmente irreversibles como resultado de intervenciones preventivas de salud pública impuestas a los hogares, como la limitación del acceso a visitantes generales y cuidadores esenciales, ausencias de residentes y actividades grupales. También ha habido un aumento en la prescripción de psicofármacos a los residentes de Ontario LTC. 
La evidencia acumulada sobre COVID-19 en los hogares de LTC de Ontario se ha aprovechado de varias maneras para respaldar las intervenciones y políticas de salud pública durante la pandemia. Varias medidas adicionales podrían ser efectivas para prevenir brotes de COVID-19, hospitalizaciones y muertes en los hogares de LTC de Ontario. Esto incluye mejorar la dotación de personal, minimizar la infección de los trabajadores de LTC, reducir el hacinamiento de los hogares de LTC, medidas mejoradas de prevención y control de infecciones (IPAC), un enfoque más equilibrado y matizado de las medidas de salud pública y estrategias adicionales para promover la aceptación de la vacuna COVID-19 entre los residentes y el personal.

Palabras clave: SARS-CoV-2, hogar de ancianos, atención colectiva, medicina geriátrica, prevención y control de infecciones

2019冠状病毒病和安大略省的长期护理院

摘要

安大略省长期护理院（长期护理, LTC）的居民因2019冠状 病毒病 (COVID-19) 和COVID-19大流行相关形势而经历了 极高的发病率和死亡率。截至2021年7月10日，共有3975名 LTC院居民死于COVID-19, 占安大略省COVID-19总死亡人数 (9245) 的 $43 \%$ 。

LTC 院是否会经历病毒爆发, 最重要的风险因素为护理院周 边社区的COVID-19每日感染率以及工作人员感染发生率。就 病毒爆发的规模和导致的居民死亡数量而言, 最重要的风险 因素为老式设计、感染链溯源和群体聚集。

安大略省LTC院的许多居民经历了严重的、潜在不可逆的生 理衰退、认知衰退、心理衰退和功能性衰退, 这归因于对护 理院强制执行的预防性公共卫生干预, 例如限制访客和必需 的护理员、居民外出和群体活动。为安大略省LTC院居民开 具精神药物处方的情况也有所增加。

大流行期间，关于安大略省LTC院COVID-19的越来越多的证 据从不同方面被用于支持公共卫生干预和政策。一些进一步 措施能有效预防安大略省LTC院的COVID-19爆发、住院治疗 
和死亡。这包括: 提升人员配备、将LTC员工感染最小化、 分散LTC院集体聚集情况、提升感染预防和控制（IPAC）措 施、更为均衡且微妙的公共卫生措施、以及用于增加居民和 员工对COVID-19疫苗的接受度的其他策略。

关键词: 严重急性呼吸综合征冠状病毒 2 , 疗养院, 集体护 理, 老年医学, 感染预防和控制

\section{Background}

The Province of Ontario has 626 licensed LTC homes and 77,257

long-stay beds. Some $58 \%$ of homes are privately owned, while $24 \%$ are non-profit/charitable, and $16 \%$ are municipal (Canadian Institute for Health Information, 2020c; Ontario Long-Term Care Association, 2020). As of February 2019, the average time to LTC placement was 161 days and the waitlist had nearly 35,000 individuals. Approximately 300 of Ontario's LTC homes, containing more than 30,000 beds, are outdated and slated for redevelopment (Ontario Long-Term Care Association, 2020).

Ontario LTC residents receive personal and nursing care as well as subsidized accommodation under a publicly funded LTC program. Most direct care in Ontario LTC homes is provided by personal support workers (PSWs) who account for $58 \%$ of the LTC workforce, with nurses accounting for an additional $25 \%$ of LTC staff (Long-Term Care Staffing Study Advisory Group, 2020). LTC homes were strongly affected during Ontario's first and second waves of the COVID-19 pandemic.

\section{Questions}

What do we know about the first, second, and third waves of COVID-19 in Ontario LTC homes?

Which risk factors are associated with COVID-19 outbreaks in Ontario LTC homes, and what are the extent and death rates associated with outbreaks?

What has the impact of the COVID-19 pandemic been on the general health and wellbeing of LTC residents? 
How has the existing Ontario evidence on COVID-19 in LTC settings been used to support public health interventions and policy changes in these settings?

What are the further measures that could be effective in preventing COVID-19 outbreaks, hospitalizations, and deaths in Ontario's LTC homes?

What was the early impact of the COVID-19 vaccine rollout on Ontario's LTC homes?

\section{Findings}

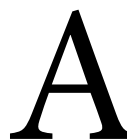
s of 2018, Ontario LTC homes reported an average of 3.7 hours of paid direct care per resident per day, including all worked hours, vacations, statutory holidays, and benefits (Long-Term Care Staffing Study Advisory Group, 2020). The actual number of direct hours of direct care received per resident per day is approximately 2.7 hours (Block \& Dhunna, 2020).

The majority (90\%) of LTC home residents live with some form of cognitive impairment, and $86 \%$ need extensive help with daily activities such as eating or toileting (Ontario Long-Term Care Association, 2020). Over the last several years, the complexity of residents living in Ontario LTC homes has substantially increased, with residents being older and having increased multimorbidity, polypharmacy and more extensive levels of physical and cognitive impairment (Ng et al., 2020). The average life expectancy of a LTC resident is approximately 18 months, and
$11.7 \%$ of Ontario residents die within one year of admission to a LTC home (Tanuseputro et al., 2015).

\section{First, Second and Third Waves of the COVID-19 Pandemic in Ontario's LTC Homes}

COVID-19 has taken a substantial toll on Ontario's LTC homes. In the first wave of the COVID-19 pandemic in Ontario's LTC homes, from March 17 to August 31, 2020, 34.0\% (212/626) of LTC homes experienced COVID-19 outbreaks, resulting in 6,036 resident cases and 1,815 resident deaths. Ontario LTC home residents accounted for $64.5 \%(1,815 / 2,812)$ of the province's COVID-19 deaths, the highest proportion among 16 other Organisation for Economic Co-operation and Development (OECD) countries (Figure 1) (Canadian Institute for Health Information, 2020b; Comas-Herrera, Zalakaín, et al., 2020; Sepulveda et al., 2020).

From April 14 to June 29, 2020, Ontario LTC homes were mandated to report all LTC resident deaths to the Office of the Chief Coroner. However, this data did not include LTC staff deaths or LTC residents who died in hospital. From April 14 to June 29, 2020, there was an excess of 1,589 deaths in Ontario LTC homes, as compared with the 5 -year historical average for the same time period (Figure 2).

A study analyzing mortality in Ontario using cremation data reported an $89 \%$ increase in LTC home resident cremations in April 2020 compared to the month of April in the 2017-2019 period (Postill et al., 2020). 

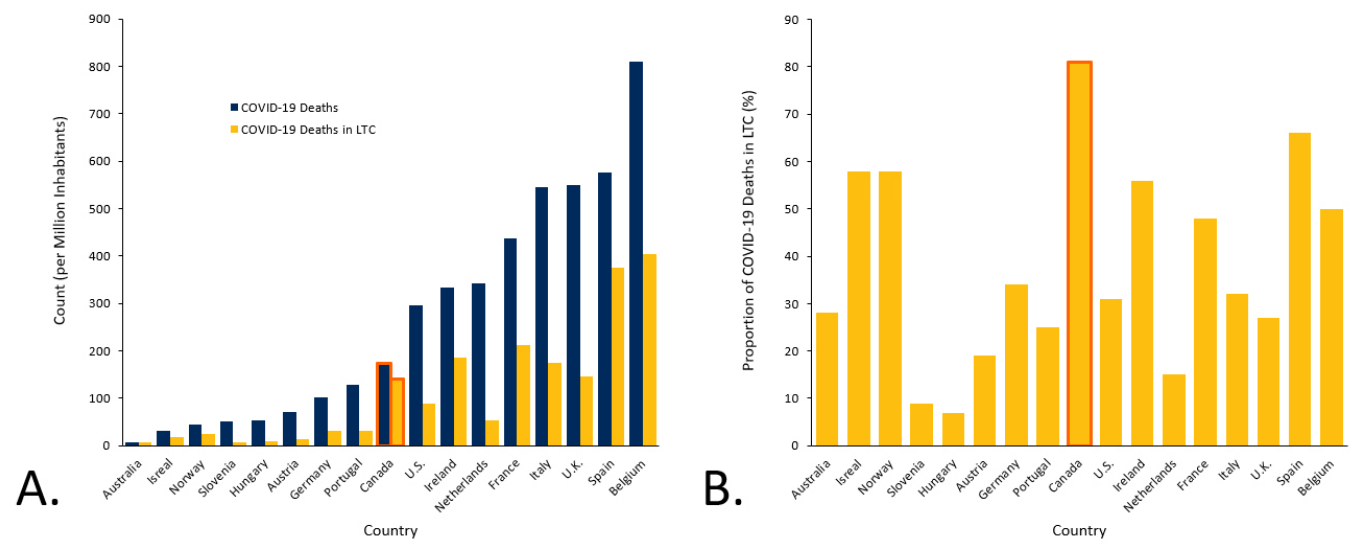

Figure 1. COVID-19 Deaths Among 16 OECD Countries, as of May 25, 2020

Bar graph A presents COVID-19 deaths among 16 OECD countries per million inhabitants as of May 25, 2020, in the population and in LTC. Bar graph B presents the proportion of COVID-19 deaths in LTC among all COVID-19 deaths in the population. Canada, at 81\%, has the highest proportion of COVID-19 deaths in LTC among the 16 other OECD countries. Figure adapted from the Canadian Institute for Health Information (CIHI) (Canadian Institute for Health Information, 2020b).

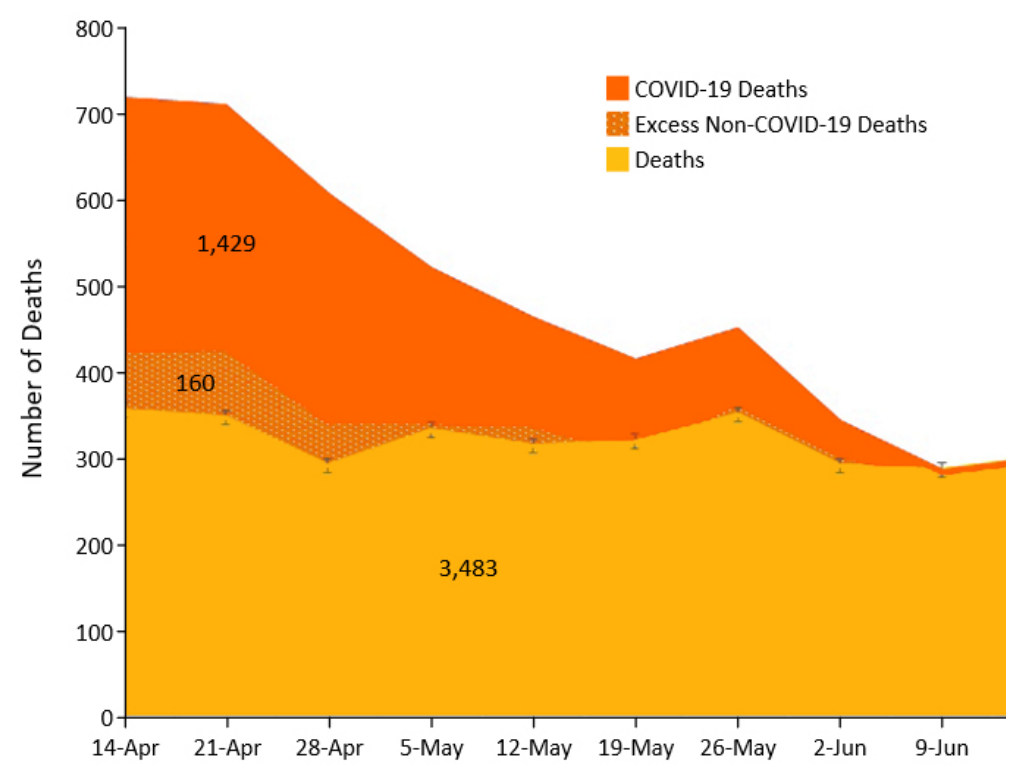

Figure 2. Excess Mortality in Ontario's LTC Homes

Graph presenting the excess mortality in Ontario's LTC homes between April 14 and June 29, 2020. Excess mortality refers to the deaths beyond what would be expected in the absence of the COVID-19 pandemic, indicating the potential burden of mortality of the COVID-19 pandemic. Between April 14 and June 29, 2020, there was an excess of 1,589 deaths in Ontario's LTC sector. Of these deaths, 1,429 were COVID-19 deaths. While the remaining 160 excess deaths were not COVID-19 deaths, they may be indirectly attributed to COVID-19 and the COVID-19 pandemic. Figure adapted from the Capacity Planning and Analytics Division, Ontario Ministry of Health (Kamil M, personal communication). 
As of July 10, 2021, a total of 3,975 Ontario LTC home residents have died of COVID-19, totaling $43.0 \%$ of all 9,245 COVID-19 deaths in Ontario to date. In addition, a total of 10 LTC staff have died of COVID-19.

The first, second, and third waves of the COVID-19 pandemic are distinct. More LTC home residents were infected in the first wave compared to community-dwelling adults aged 70 years and older, with the opposite phenomenon occurring in the second and third waves (Figure 3). Provincial SARS-CoV-2 testing capacity has improved, resulting in both improved and earlier case detection in the second wave while widespread COVID-19 vaccination markedly reduced cases in the third wave.

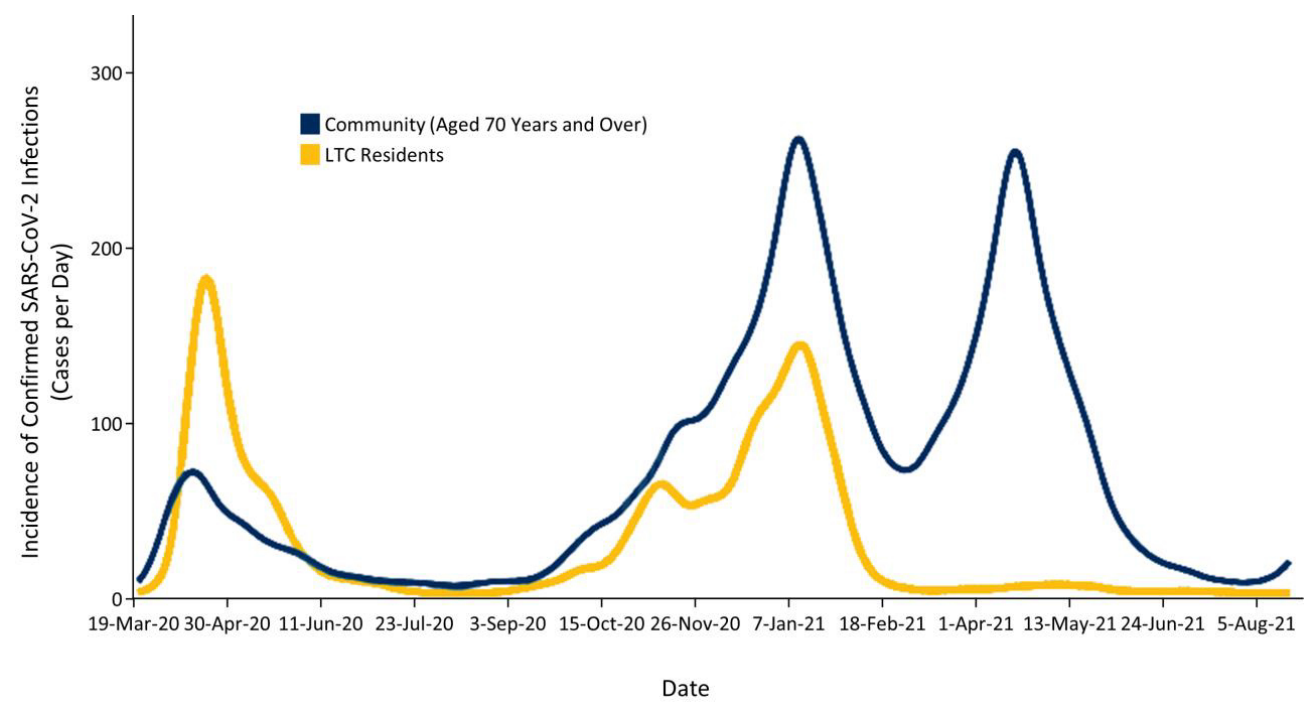

Figure 3. Incidence of SARS-CoV-2 Infections in Ontario Among LTC and Community Residents

Graph presenting the daily incidence of confirmed SARS-CoV-2 infections in Ontario among community-dwelling residents aged 70 years and older and LTC home residents, from March 2020 to August 2021. The date is based on the date of reporting. Data sourced from the Case and Contact Management System (CCM Plus). Note that the number of community-dwelling adults aged 70 years and over ( $n=1.7$ million) is more than 20 times higher than the number of LTC residents $(n=\sim 75,000)$. Therefore, the risk of confirmed SARS-CoV-2 infection is dramatically higher in LTC residents as compared with community-dwelling adults aged 70 years and over. Figure adapted from Public Health Ontario (Government of Canada, 2020b; Public Health Ontario, 2020a).

With these differences in mind, data comparing the first, second, and third waves reveals notable differences in key indicators in the LTC sector.

Compared to the first wave, the SARS-CoV-2 infection rate among LTC residents has been lower (Figure 4), and its doubling time has been longer (Figure 5) in the second and third waves. An increased doubling time indicates a slower growth rate of infections. 


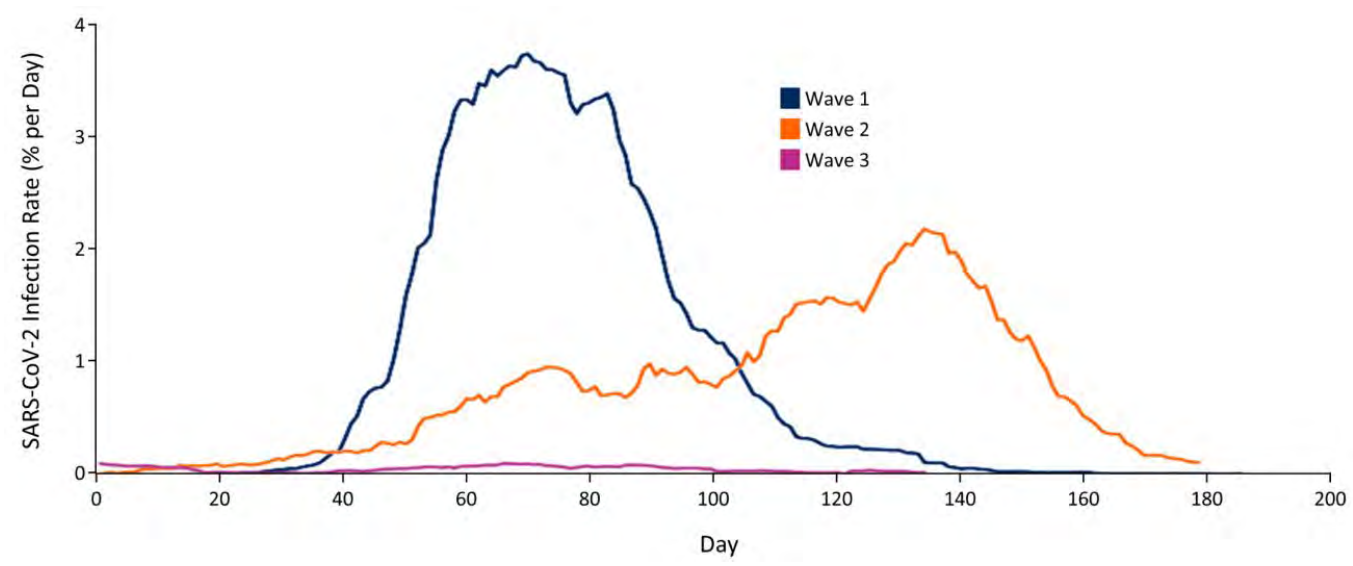

Figure 4. SARS-CoV-2 Infection Rate Among LTC Home Residents in Ontario, as of July 15, 2021

Graph presenting the rate of confirmed SARS-CoV-2 infections per day among LTC home residents in Ontario. Day 0 for Wave 1 is February 26, 2020; however, data collection began from March 17, 2020. Day 0 for Wave 2 is September 1, 2020. Day 0 for Wave 3 is March 1, 2021. Data sourced from the integrated Public Health Information System (iPHIS), extracted July 15, 2021. Figure adapted from Malikov K (personal communication).

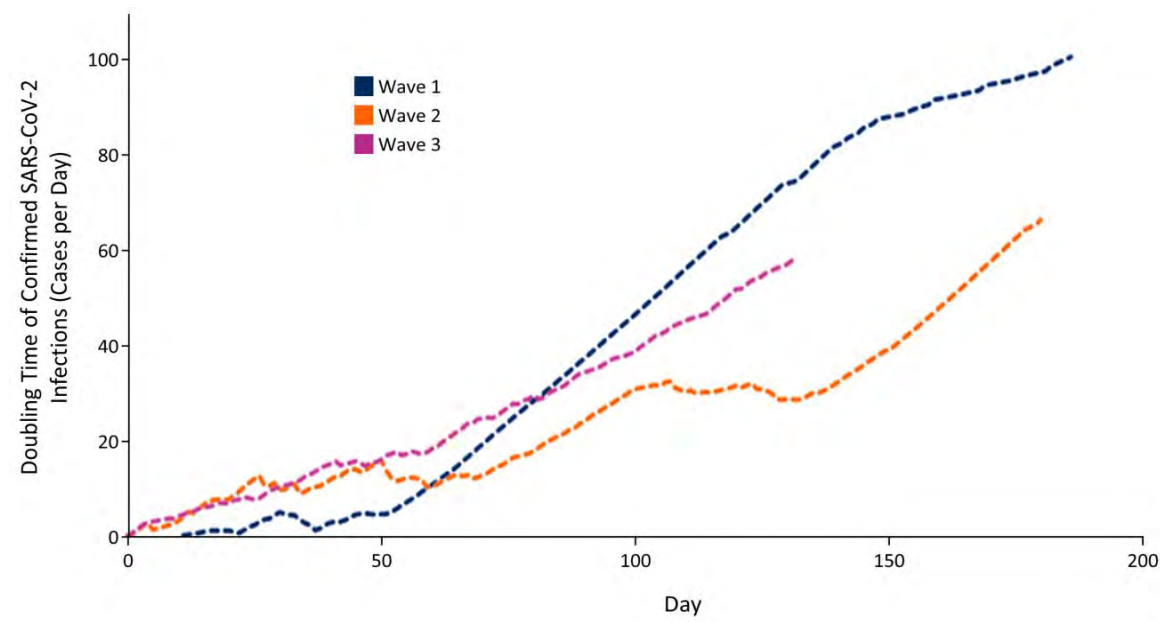

Figure 5. Doubling Time of SARS-CoV-2 Infections in Among LTC Home Residents in Ontario, as of July 15, 2021

Graph presenting an analysis of the doubling time of SARS-CoV-2 infections among LTC home residents in Ontario. Day 0 for Wave 1 is February 26, 2020; however, data collection began from March 17, 2020. Day 0 for Wave 2 is September 1, 2020. Day 0 for Wave 3 is March 1, 2021. Data sourced from the integrated Public Health Information System (iPHIS), extracted July 15, 2021. Figure adapted from Malikov K (personal communication).

There has also been a faster dents in the first wave, as compared to rate and greater number of LTC home the second and especially third wave COVID-19 outbreaks involving resi- (Figure 6). 


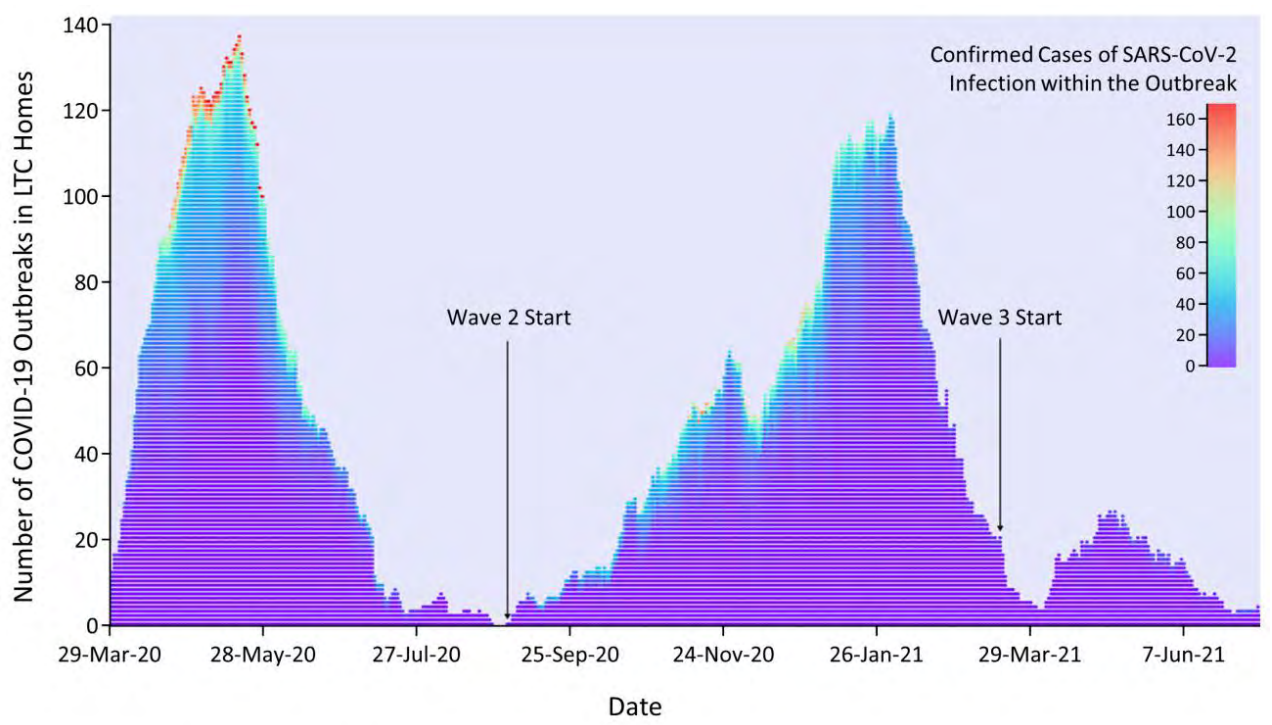

Figure 6. Number of COVID-19 Outbreaks and Respective SARS-CoV-2 Infections in Ontario's LTC Homes

Graph presenting the number of COVID-19 outbreaks and number of SARS-CoV-2 infections within each outbreak in Ontario's LTC homes, from March 29 to July 15, 2021. Presented outbreaks involve at least one LTC home resident. The date is based on the date of reporting. There are fewer outbreaks in the second wave that involve more than 100 cases of confirmed SARSCoV-2 infections. Data sourced from the integrated Public Health Information System (iPHIS), extracted July 15, 2021. Figure adapted from Malikov K (personal communication).

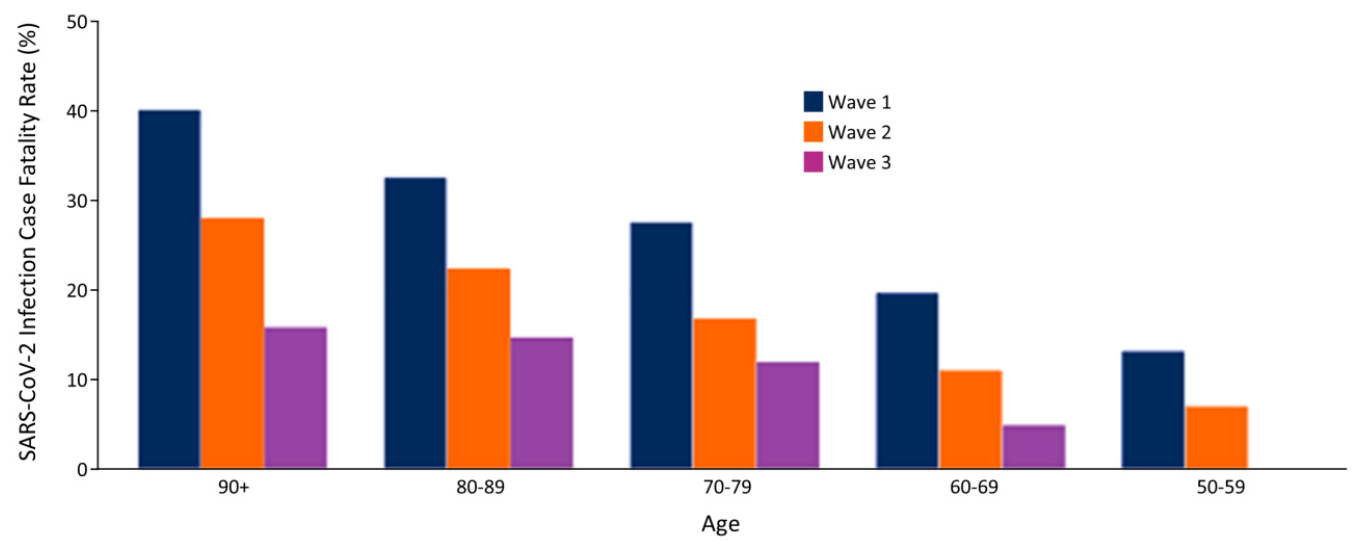

Figure 7. Case Fatality Rate of Ontario LTC Home Residents with SARS-CoV-2 Infections, as of December 16, 2020

Bar graph presenting case fatality rates of confirmed SARS-CoV-2 infections among Ontario LTC home residents by age group. Wave 1 case fatality rates are from February 26 to August 31, 2020. Wave 2 case fatality rates are from September 1, 2020, to February 28, 2021. Wave 3 case fatality rates are from March 1 to July 15, 2021. Data sourced from the integrated Public Health Information System (iPHIS), extracted July 15, 2021. Figure adapted from Malikov K (personal communication). 
This observed improvement is likely multifactorial in cause: As the pandemic progresses, there is a much clearer understanding and detection of asymptomatic and pre-symptomatic spread of SARS-CoV-2 infection, as well as atypical presentations of COVID-19, which are more common among LTC home residents (Arons et al., 2020; Goldberg et al., 2020; Hoxha et al., 2020). There is better access to SARS-CoV-2 testing and personal protective equipment (PPE), which were both severely restricted at the onset of the first wave in the LTC sector. Most homes have now implemented more robust IPAC measures, including universal masking of staff and limiting them to work at only one healthcare setting (Dunning et al., 2020). There has also been an intensification of efforts to manage residents with SARSCoV-2 infection in LTC homes, with interventions such as supplemental oxygen, subcutaneous hydration, and dexamethasone therapy (Government of Canada, 2020a; Jüni et al., 2020; Stall, Farquharson, et al., 2020).

An analysis of hospitalizations among all Ontarians who died of COVID-19 from March to November 2020 revealed that only a small proportion of Ontario LTC home residents were hospitalized prior to death. There were also substantial temporal variations, with hospitalizations paradoxically reaching their lowest point when the overall incidence of SARS-CoV-2 infections peaked in April, 2020 (Table 1) (Brown, Daneman, et al., 2020)nursing home residents have experienced disproportionately high COVID-19 mortality due to the intersection of congregate living, multimorbidity, and advanced age. Among 12 OECD countries, Canada has had the highest proportion of COVID-19 deaths in nursing home residents $(78 \%$. While many LTC home residents may have had pre-pandemic directives indicating that they should not be sent to an acute care hospital, the low admission rate of $15.5 \%$ observed between March and April 2020 was in contrast to higher admission rates of greater than $30 \%$ in subsequent months and comparatively stable

There were also notable sexbased differences, with women dying of COVID-19 being less likely to receive hospitalization compared to men in both community $(76.9 \%$ women vs $81.7 \%$ men) and LTC home $(22.1 \%$ women vs $27.7 \%$ men) settings. These sex-based differences are consistent with earlier Ontario and international findings reporting increased rates of hospitalization among older men compared to older women (Rochon et al., 2020; Stall, Wu, et al., 2020). Further, the observed sex- and gender-based differences in end-of-life care for Ontario LTC home residents dying of COVID-19 are consistent with pre-pandemic evidence reporting that male residents with advanced dementia are much more likely than female residents to be transferred to hospital in their last 30 days of life (Stall et al., 2019).

Overall, the findings of this analysis substantiate reports suggesting that hospitalizations for LTC home residents with COVID-19 were low during the peak of the pandemic's first wave, 
which may have contributed to the par- Ontario's LTC homes.

ticularly high COVID-19 mortality in

Table 1. Hospital Admissions Prior to Death Among Community and LTC Home Residents with COVID-19

\begin{tabular}{|c|c|c|c|c|c|c|}
\hline & \multicolumn{3}{|c|}{ Community Residents } & \multicolumn{3}{|c|}{ LTC Home Residents } \\
\hline & $\mathbf{N}$ & $\begin{array}{c}\text { Hospital- } \\
\text { ized prior } \\
\text { to death, } \\
\mathrm{N}(\%)\end{array}$ & p-value & $\mathbf{N}$ & $\begin{array}{c}\text { Hospital- } \\
\text { ized prior } \\
\text { to death, } \\
N(\%)\end{array}$ & p-value \\
\hline Total & 1,363 & $\begin{array}{c}1081 \\
(79.3)\end{array}$ & & 2,345 & $570(24.3)$ & \\
\hline \multicolumn{7}{|l|}{ Month (2020) } \\
\hline March-April & 535 & $425(79.4)$ & \multirow{4}{*}{$<0.001$} & 1,032 & $164(15.9)$ & \multirow{4}{*}{$<0.001$} \\
\hline May & 306 & $253(82.7)$ & & 732 & $198(27.0)$ & \\
\hline June-July & 142 & $127(89.4)$ & & 168 & $69(41.1)$ & \\
\hline $\begin{array}{l}\text { August- } \\
\text { October }\end{array}$ & 163 & $123(75.5)$ & & 126 & $36(28.6)$ & \\
\hline November & 217 & $153(70.5)$ & & 287 & $103(35.9)$ & \\
\hline \multicolumn{7}{|l|}{ Age (years) } \\
\hline$<70$ & 339 & $273(80.5)$ & \multirow{4}{*}{$<0.001$} & 153 & $63(41.2)$ & \multirow{4}{*}{$<0.001$} \\
\hline $70-79$ & 300 & $261(87.0)$ & & 344 & $102(29.7)$ & \\
\hline $80-89$ & 428 & $340(79.4)$ & & 918 & $227(24.7)$ & \\
\hline$\geq 90$ & 296 & $207(69.9)$ & & 930 & $178(19.1)$ & \\
\hline \multicolumn{7}{|l|}{ Gender $^{\mathrm{a}}$} \\
\hline Male & 760 & $621(81.7)$ & \multirow{2}{*}{0.03} & 963 & $267(27.7)$ & \multirow{2}{*}{0.002} \\
\hline Female & 598 & $460(76.9)$ & & 1,355 & $300(22.1)$ & \\
\hline
\end{tabular}

Table presenting hospital admissions prior to COVID-19 death among community and LTC home residents, from March to November 2020. ${ }^{a}$ Deaths with unknown gender are not presented below due to small cell counts. Table adapted from Brown et al. J Am Med Dir Assoc. 2021 (Brown, Daneman, ... et al., 2021). The p-values are for differences across periods, age and gender.

Risk Factors for COVID-19

Outbreaks and Resident Deaths in

\section{Ontario's LTC Homes}

The risk of COVID-19 outbreaks in LTC homes is strongly associated with the rate of SARS-CoV-2 infection in the communities surrounding them. How- ever, the temporal relationship between rising rates of SARS-CoV-2 infection in the community and the risk threshold for subsequent LTC home outbreaks is not well defined (Ouslander \& Grabowski, 2020; White et al., 2020) administrative data, state reports of SNF outbreaks, and data from Genesis 


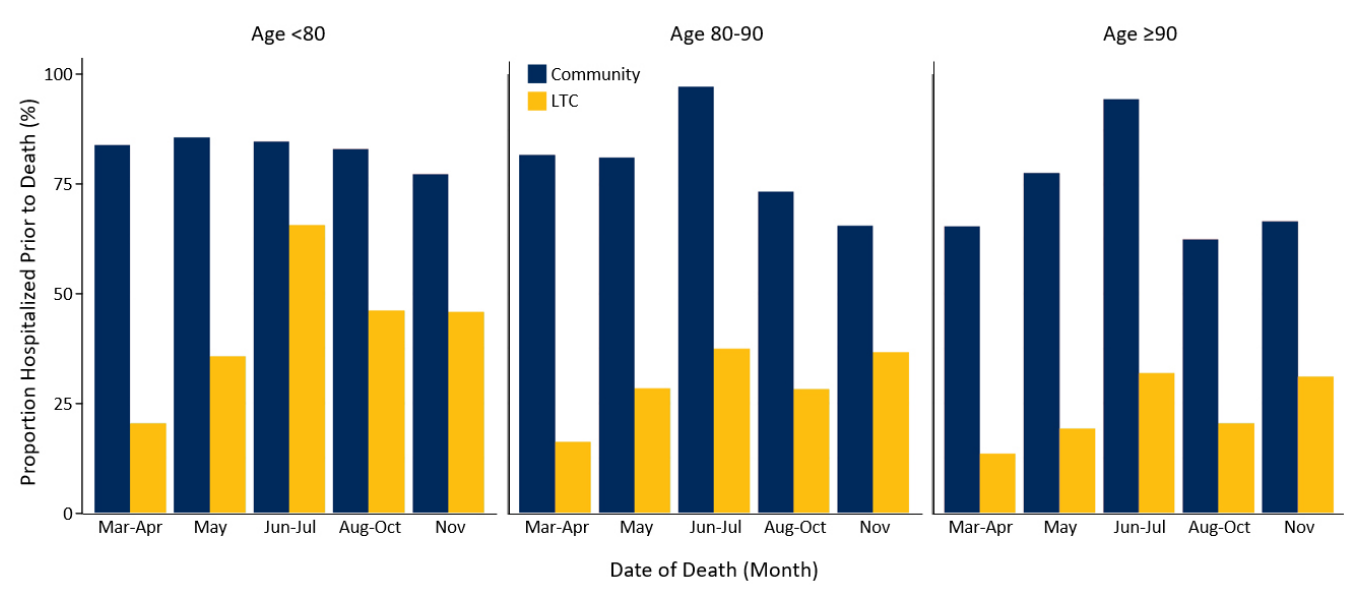

Figure 8. Hospital Admissions Prior to Death Among Community and LTC Home Residents with COVID-19 by Age Group

Bar graph presenting the proportion of hospitalization prior to COVID-19 death among community and LTC home residents by age group, from March through November 2020. Figure adapted from Brown et al. J Am Med Dir Assoc. 2021 (Brown, Daneman, et al., 2021.

HealthCare, a large multistate provider of post-acute and long-term care. State data are reported as of April 21, 2020; Genesis data are reported as of May 4, 2020.InSETTING AND PARTICIPANTS: The Genesis sample consisted of 341 SNFs in 25 states, including a subset of 64 SNFs that underwent universal testing of all residents. The non-Genesis sample included all other SNFs $(\mathrm{n}=3,016$.

A population-based cohort study of all Ontario COVID- 19 cases between March 1 and July 16, 2020 evaluated the temporal relationship between trends in the number of active community COVID-19 cases and the number of LTC home outbreaks (Malikov et al., 2020). The average lag time between community cases and LTC home outbreaks was 23 days for Ontario overall, with substantial variability across geographic regions, ranging from 11 to 43 days (Figure 10). The longest lag was ob- served in the North Region, which has a low population density and reported a lower cumulative COVID-19 incidence of $0.3 \%$ in LTC home residents, compared to the provincial average of $7.5 \%$ over the study's time period.

The analysis also determined the levels of community incidence associated with a $75 \%$ probability of observing a LTC home outbreak within 5 days. For the province overall, a daily incidence of 2.30 SARS-CoV-2 infections per 100,000 inhabitants was associated with a $75 \%$ probability of a LTC home outbreak occurring five days later (Table 2).

The lag days estimate is a useful early warning indicator for surveillance systems and provides a time window-23 days for Ontario overallduring which the LTC sector should rapidly mobilize and intensify occupational health and IPAC processes to 


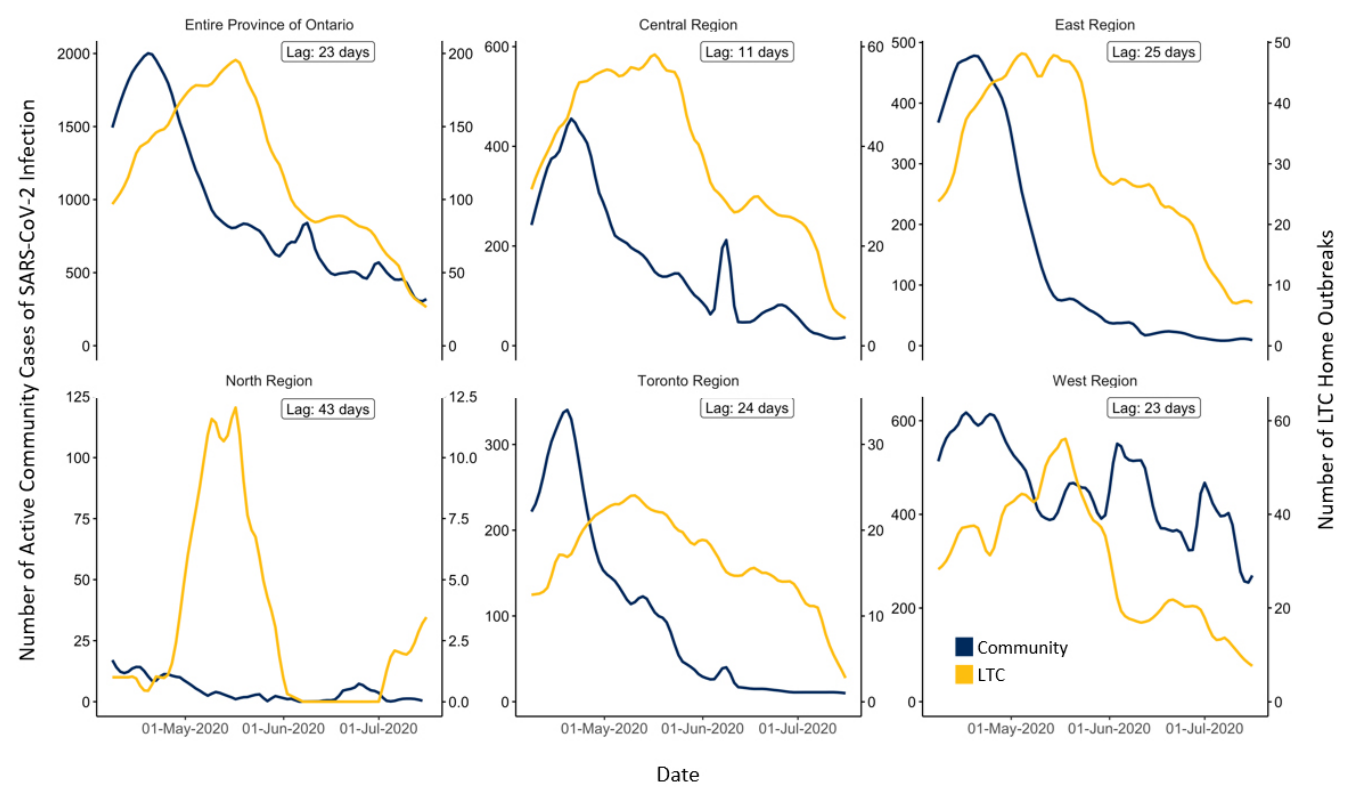

Figure 9. Community Incidence of SARS-CoV-2 Infection and Outbreaks in Ontario's LTC Homes

Graphs presenting the daily incidence of confirmed SARS-CoV-2 infections within communities and COVID-19 outbreaks in LTC homes in Ontario by region, from April 8 to July 16, 2020. Includes data on 623 LTC homes in Ontario. Lag refers to the lag time between community cases and LTC home outbreaks. Figure adapted from Malikov et al. J Am Med Dir Assoc. 2021 (Malikov et al., 2021).

both prevent and mitigate COVID-19 outbreaks, following an observed rise in community infections. The reported thresholds for community infections at which outbreaks in LTC homes first occur are useful both for guiding broader public health interventions to targeting community transmission-such as the province's tiered response frameworkand for guiding policies based on community incidence of SARS-CoV-2 infections that concern visitors to LTC homes as well as resident absences and congregate activities such as dining (Government of Ontario, 2020b, 2020).

The relationship between community incidence of SARS-CoV-2 infections and LTC home outbreaks is likely mediated by infected staff who are unknowingly importing virus in homes with asymptomatic or pre-symptomatic COVID-19 (Chow et al., 2020; Vijh et al., 2020). An Ontario study conducted in the early days of the first wave of the COVID-19 pandemic, from March 29 to April 7, 2020, reported that infection among LTC staff was associated with death among residents with a 6-day lag (Figure 10) (Fisman et al., 2020).

Additional Ontario studies from the first wave of the pandemic confirm that community incidence of SARS$\mathrm{CoV}-2$ infections is the strongest predictor of whether a LTC home is going to experience a COVID-19 outbreak (Brown et al., 2020; Stall et al., 2020). 
Table 2. Characteristics of Ontario's LTC Homes and Thresholds for Community Incidence of SARS-CoV-2 Infections Associated with a 75\% Probability of LTC Home Outbreaks after 5 Days

\begin{tabular}{lccccc}
\hline Region & $\begin{array}{c}\text { Popu- } \\
\text { lation } \\
\text { density } \\
\text { per } \\
\mathbf{k m}^{2 \mathbf{a}}\end{array}$ & $\begin{array}{c}\text { Number } \\
\text { of LTC } \\
\text { homes }\end{array}$ & $\begin{array}{c}\text { Number } \\
\text { of LTC } \\
\text { home } \\
\text { resi- } \\
\text { dents }\end{array}$ & $\begin{array}{c}\text { Cumulative } \\
\text { SARS-CoV-2 } \\
\text { infections } \\
\text { in LTC } \\
\text { residents }\end{array}$ & $\begin{array}{c}\text { Threshold of daily } \\
\text { active SARS-CoV-2 } \\
\text { infections per 100,000 } \\
\text { associated with a 75\% } \\
\text { probability of a future } \\
\text { LTC home outbreak } \\
\text { after 5 days }\end{array}$ \\
\hline Central & 294.4 & 123 & 17,315 & 2,273 & 2.93 \\
East & 64.7 & 165 & 20,327 & 1,936 & 1.88 \\
North & 1.0 & 63 & 6,495 & 17 & - \\
Toronto & $6,412.6$ & 36 & 5,695 & 739 & 3.52 \\
West & 94.9 & 236 & 25,844 & 716 & 1.83 \\
Ontario & 14.8 & 623 & 75,676 & 5,681 & 2.30 \\
\hline
\end{tabular}

Table presenting characteristics of Ontario's LTC homes and thresholds for community incidence of SARS-CoV-2 infections associated with a 75\% probability of LTC home outbreaks after 5 days, from March 1 to July 16, 2020. 'Data sourced from Ontario Ministry of Finance, based on 2016 Canadian Census (Ministry of Finance, 2020). ${ }^{b}$ Daily active SARS-CoV-2 infections in the community per 100,000 inhabitants. ${ }^{~}$ Threshold calculations for the North Region were suppressed due to the small numbers of reported cases and small population size. 623 of Ontario's LTC homes are included. Table adapted from Malikov et al. J Am Med Dir Assoc. 2021(Malikov et al., 2021).

An earlier retrospective cohort study examining the impact of for-profit status on COVID-19 outcomes in 623 Ontario LTC homes, from March 29 to May 20, 2020, found that for-profit status had no significant association with the risk of outbreaks. However, the study found that each additional cumulative COVID-19 case per 1,000 individuals in the public health unit region surrounding the LTC care home was associated with nearly double the odds of an outbreak (adjusted odds ratio (OR) 1.91, 95\% confidence interval (CI) 1.19-3.05) (Stall et al., 2020).
Homes with for-profit status had outbreaks with nearly twice as many residents infected (adjusted risk ratio (RR) $1.96,95 \%$ CI $1.26-3.05$ ) and $78 \%$ more resident deaths (adjusted RR 1.78, 95\% CI 1.03-3.07), compared with non-profit homes.

These associations were largely explained by the higher proportion of older design standards that meet or fall below design standards established in the year 1972, and chain ownership in homes with for-profit status (Figures 12 and 13). 


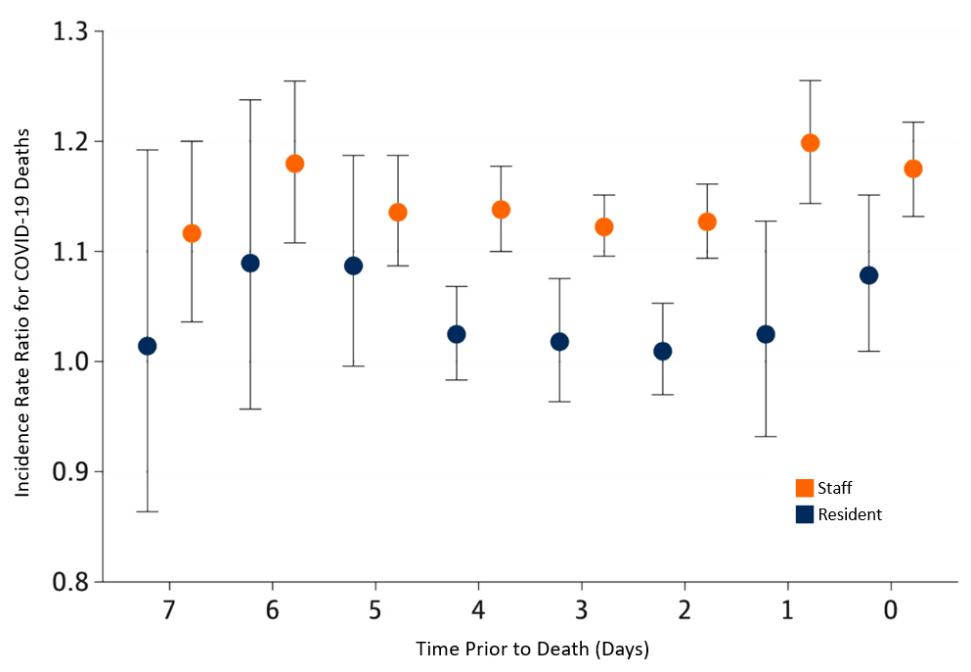

Figure 10. Incidence Rate Ratios for Deaths by Lagged Infections Among LTC Residents and Staff in Ontario

Graph presenting the incidence rate ratios for COVID-19 deaths by lagged confirmed SARS-CoV-2 infections among LTC residents and staff in Ontario, from March 29 to April 7, 2020. Circles represent incidence rate ratios. Vertical lines represent 95\% confidence intervals (CI). An elevated risk of COVID-19 death is observed at all lag times after SARS-CoV-2 infection among LTC staff. Figure adapted from Fisman et al. Jama Netw Open. 2020 (Fisman et al., 2020).

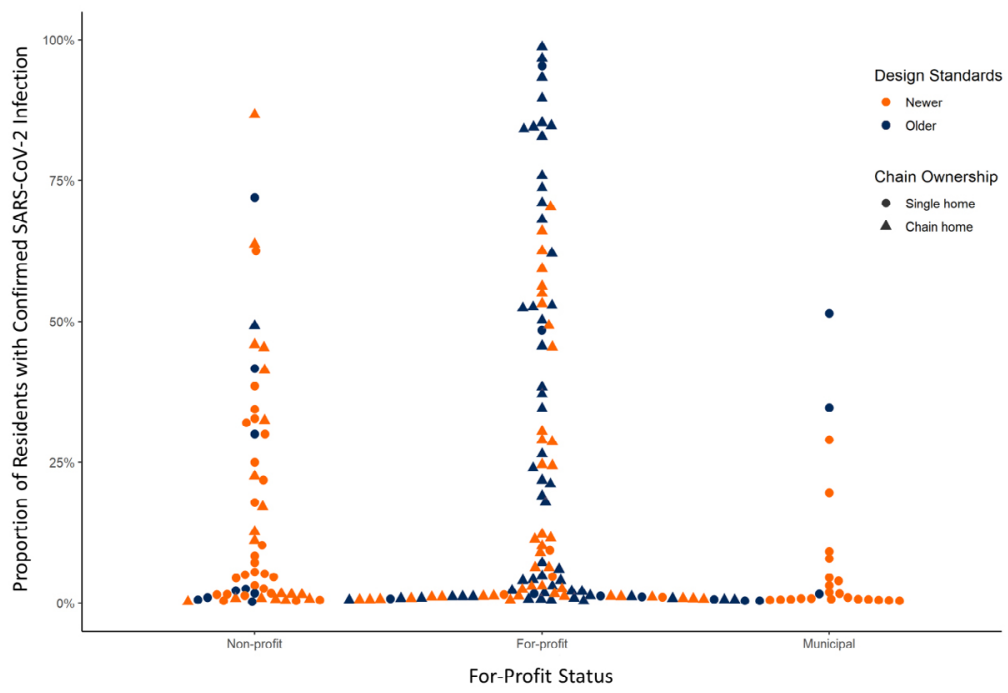

Figure 11. Proportion of Residents with SARS-CoV-2 Infection Among LTC Homes in Outbreak by Profit Status

Graph presenting the extent (i.e., the percentage of confirmed SARS-CoV-2 infections among residents of a LTC home) of COVID-19 outbreaks in Ontario LTC homes by profit status, from March 29 to May 20, 2020. Homes with older design standards and chain ownership, which are more common among for-profit status homes, had the highest proportion of LTC residents with confirmed SARS-CoV-2 infections. Figure adapted from Stall et al. CMAJ. 2020 (Stall, Jones, et al., 2020). 


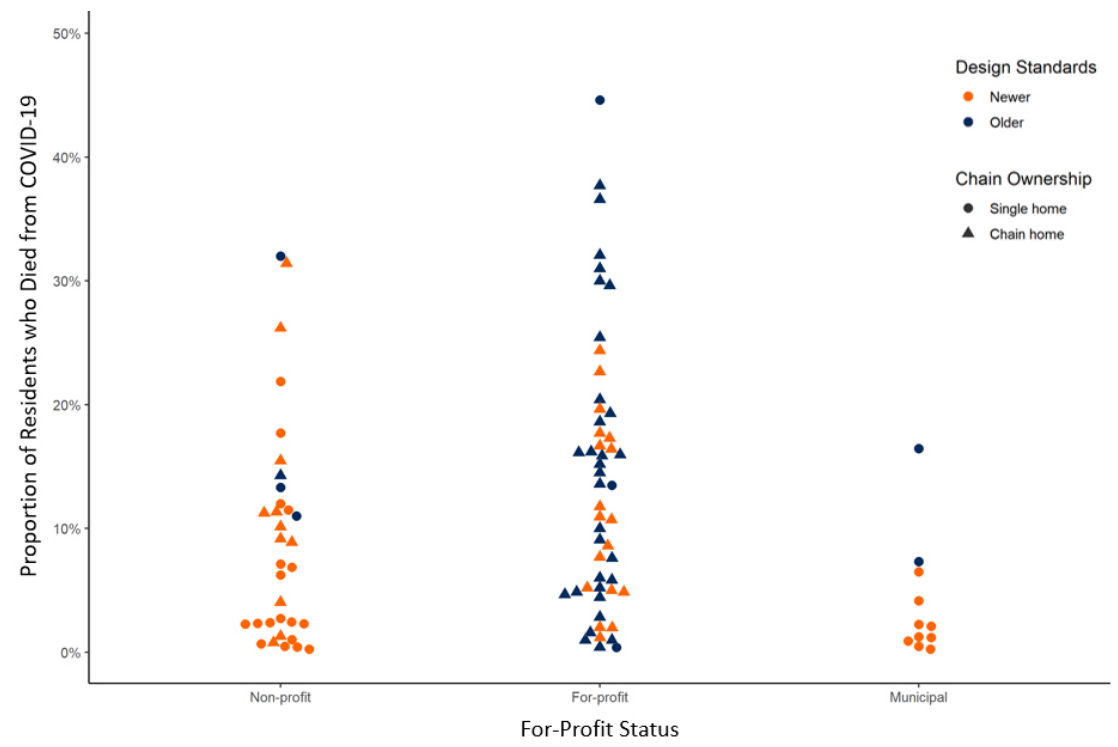

Figure 12. Proportion of Ontario LTC Residents Who Died of COVID-19 Among LTC Homes in Outbreak by Profit Status

Graph presenting the percentage of COVID-19 deaths among LTC homes in outbreak by profit status in Ontario, from March 29 to May 20, 2020. Homes with older design standards and chain ownership, with are more common among for-profit status homes, had the highest proportion of LTC residents with confirmed SARS-CoV-2 infections. Figure adapted from Stall et al. CMAJ. 2020 (Stall, Jones, et al., 2020).

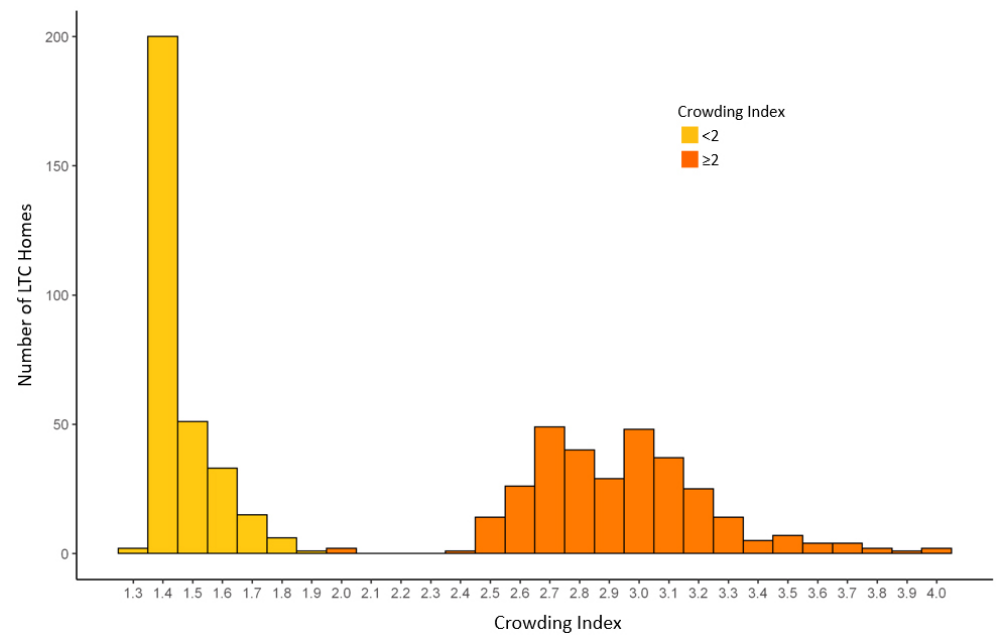

Figure 13. Distribution of Ontario LTC Homes by Crowding Index, as of March 29, 2020

Bar graph presenting the distribution of Ontario LTC homes by crowding index across 618 LTC homes, as of March 29, 2020. The crowding index for Ontario's LTC homes was derived by calculating the mean number of occupants per room and bathroom across an entire LTC home (Number of residents $\div(1 / 2$ Number of bedrooms $+1 / 2$ Number of bathrooms)). Homes with a crowding index of less than 2 were defined as having low crowding, while homes with a crowding index greater or equal to 2 were defined as having high crowding. Figure adapted from Brown et al. JAMA Intern Med. 2020 (Brown, Jones, et al., 2020). 
Another retrospective population-based cohort study examined the association between LTC home crowding and SARS-CoV-2 infection and COVID-19 mortality in Ontario LTC homes from March 29 to May 20, 2020 (Brown, Jones, et al., 2020). As of March 29, 2020, there were 78,607 resident beds in Ontario's LTC homes, with $36.9 \%$ in single-bedded rooms, $37.3 \%$ in double-bedded rooms, and $25.8 \%$ in quadruple-bedded rooms. While $50.1 \%$ (310) of LTC homes had low crowding, $49.9 \%$ (308) of LTC homes had high crowding according to a crowding index (Figure 13).

As of May 20,2020, SARS-CoV-2 infections were distributed unequally across Ontario's LTC homes, with $86 \%(4,496)$ of infections occurring in just $10 \%$ (63) of homes. The incidence of SARS-CoV-2 infections in highly crowded homes was $9.7 \%$, while the incidence of SARS-CoV-2 infection in less crowded homes was $4.5 \%$ ( $p$-value $<0.001$ ). Similarly, mortality was $2.7 \%$ in highly crowded homes and $1.3 \%$ in less crowded homes $(\mathrm{p}<0.001)$.

The probability of SARS-CoV-2 infection introduction into a home did not differ according to the crowding index, with $31.3 \%$ in high crowding homes and $30.2 \%$ in low crowding homes $(p=0.79)$. Outbreaks in crowded LTC homes were also larger: $90 \%$ of the province's LTC outbreaks involving more than 100 infected residents occurred in high crowding homes, as compared with only $10 \%$ that occurred in low crowding homes (Figure 14).

Unadjusted and adjusted regres- sion models based on the crowding index suggests that compared to a home with an index of 1.5 , homes with an index of 3 had nearly double the incidence of SARS-CoV-2 infection (RR, 2.05; 95\% CI, 1.49-2.70; adjusted RR, $1.73 ; 95 \% \mathrm{CI}, 1.10-2.72)$ and COVID-19 mortality (unadjusted RR, 1.97; 95\% CI, 1.36-2.84; adjusted RR, 1.69 ; $95 \% \mathrm{CI}$, 0.99-2.78) (Figure 15). The crowding index was not associated with the probability of introduction of SARS-CoV-2 infection into a LTC home, with the incidence of SARS-CoV-2 infection in the region surrounding a LTC home remaining the most important predictor.

Simulations suggest that $19.1 \%$ (998) of infections and $18.1 \%$ (263) of deaths in Ontario LTC homes may have been prevented if quadruplebedded rooms had been converted to double-bedded rooms. In this simulation scenario, an additional 5,070 double-bedded rooms would have been needed to maintain capacity across the province of Ontario. In a simulation where all multiple-occupancy rooms were converted to single-occupancy rooms, it was estimated that $31.4 \%$ $(1,641)$ infections and $30.1 \% \quad(437)$ deaths may have been prevented. In this scenario, an additional 29,871 new single-occupancy rooms would have been required (Brown, et al., 2020).

Taken together, evidence from Ontario suggests that the risk factors for COVID-19 outbreaks are distinct from the risk factors for spread of SARSCoV-2 infection and COVID-19 deaths within a home. The most important risk factors for whether a LTC home is 


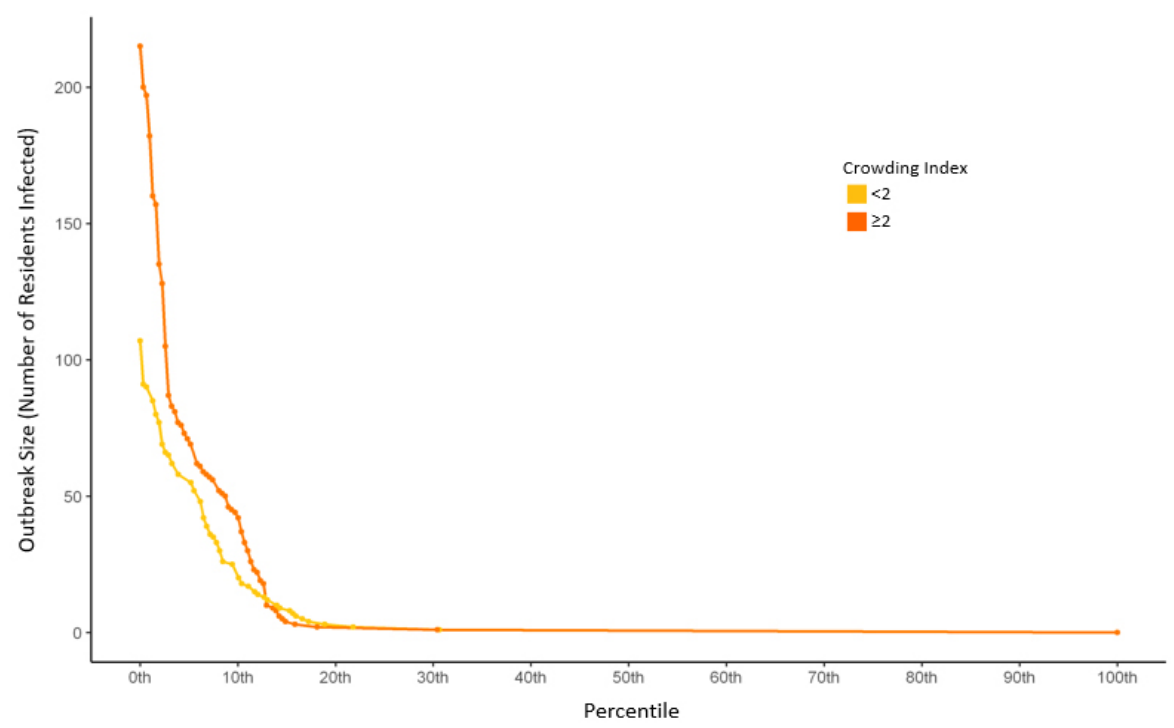

Figure 14. COVID-19 Outbreak Size by LTC Home Crowding in Ontario, from March 29 to May 20, 2020

Graph presenting the size of COVID-19 outbreaks and percentile rank of outbreak size in Ontario LTC homes by crowding index, from March 29 to May 20, 2020. It includes 618 Ontario LTC Homes. The crowding index for Ontario's LTC homes was derived by calculating the mean number of occupants per room and bathroom across an entire LTC home (Number of residents $\div(1 / 2$ Number of bedrooms $+1 / 2$ Number of bathrooms $))$. Homes with a crowding index of less than 2 were defined as having low crowding, while homes with a crowding index greater or equal to 2 were defined as having high crowding. Nine out of the 10 largest outbreaks involving more than 100 residents occurred in LTC homes with a crowding index $\geq 2$ (orange curve). Figure adapted from Brown et al. JAMA Intern Med. 2020 (Brown, Jones, et al., 2020).

going to experience a COVID-19 outbreak is the community incidence of SARS-CoV-2 infection surrounding a LTC home and staff SARS-CoV-2 infection (Fisman et al., 2020; Malikov et al., 2020). The most important risk factors for the size of a LTC home COVID-19 outbreak and the number of resident deaths are for-profit status and crowding. For-profit homes have a higher proportion of older design standards and chain ownership and crowded homes have an increased number of residents per room and bathroom (Figure 16) (Brown, et al., 2020; Stall, et al., 2020).

\section{Impact of the COVID-19}

\section{Pandemic on the Health and Wellbeing of LTC Residents}

In response to an intensifying COVID-19 crisis in Ontario LTC homes, Ontario implemented strict bans on visitors in mid-March 2020, with the goal of preventing the introduction of SARS-CoV-2 infection into the homes (Dunning et al., 2020). These measures resulted in the immediate restriction of visitors, volunteers and non-essential personnel from entering LTC homes, which restricted entry for family caregivers who provide direct, 


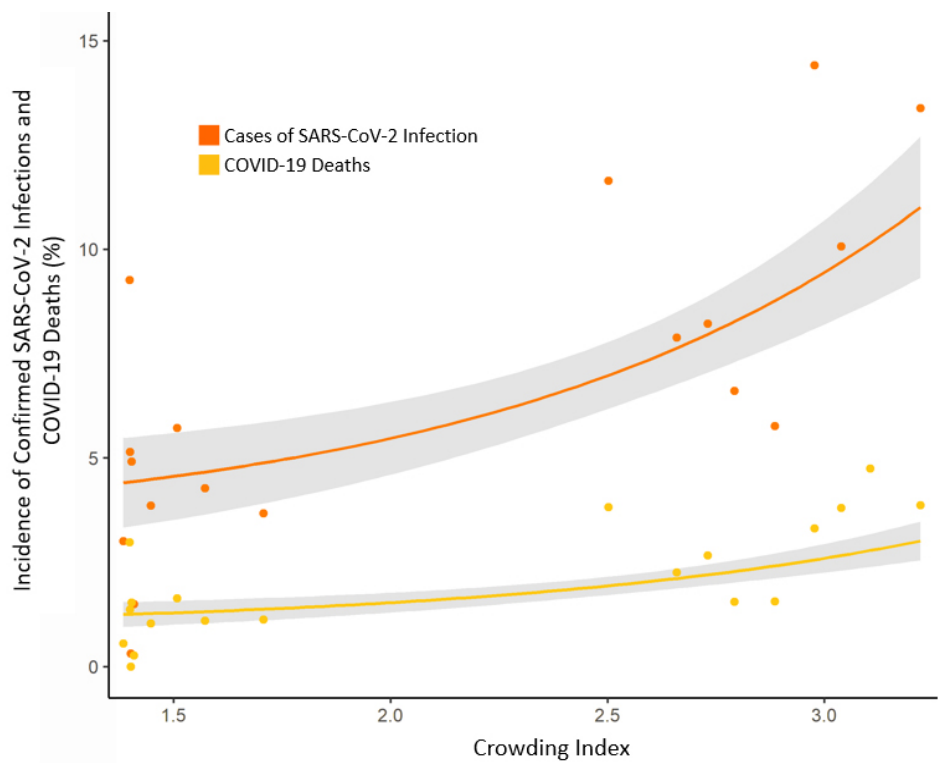

Figure 15. Incidence of SARS-CoV-2 Infections and COVID-19 Deaths by LTC Home Crowding, from March 29 to May 20, 2020

Graph presenting the incidence of SARS-CoV-2 infections and COVID-19 deaths in Ontario LTC homes by crowding index, March 29 to May 20, 2020. Grey area represents the 95\% confidence interval (CI). The crowding index for Ontario's LTC homes was derived by calculating the mean number of occupants per room and bathroom across an entire LTC home (Number of residents $\div(1 / 2$ Number of bedrooms $+1 / 2$ Number of bathrooms $)$ ). Homes with a crowding index of less than 2 were defined as having low crowding, while homes with a crowding index greater or equal to 2 were defined as having high crowding. Figure adapted from Brown et al. JAMA Intern Med. 2020 (Brown, Jones, et al., 2020).

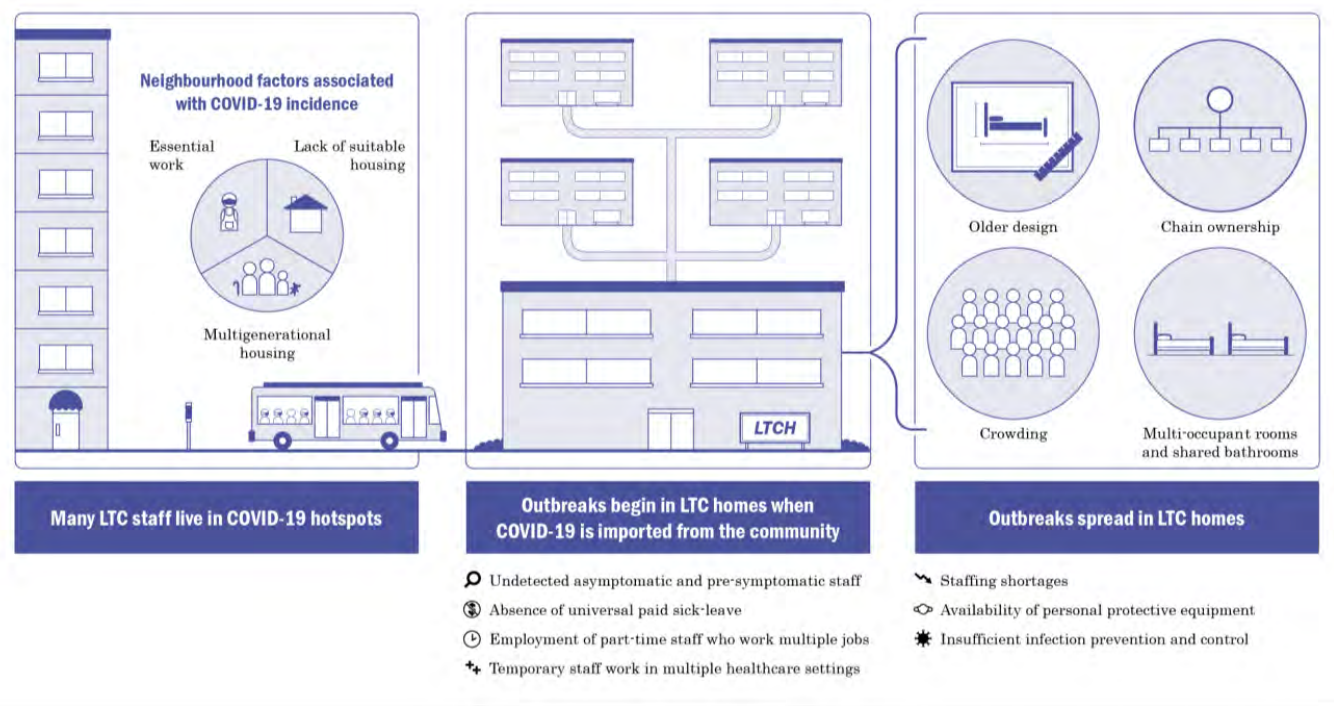

Figure 16. Anatomy of Outbreaks and Spread of COVID-19 in LTC Homes and Among Residents

Figure from Peter Hamilton, personal communication. 
complex, intense, and unpaid care for many LTC home residents (Committee on Family Caregiving for Older Adults et al., 2016; Hado \& Feinberg, 2020; Schlaudecker, 2020).

Additional restrictions resulted in the cancellation of group activities, communal dining, and restricted residents from leaving the property of LTC homes, even for short walks and fresh air. As a result, countless LTC home residents experienced severe and potentially irreversible harm, with many sustaining physical, cognitive, psychological and functional declines (Abbasi, 2020; Cagnin et al., 2020; Low, 2020; Suarez-Gonzalez, 2020; Van der Roest et al., 2020). This constellation of resident clinical issues associated with restrictive IPAC measures in LTC homes has been termed "confinement syndrome," a term appropriated from the medical literature describing the symptoms experienced by persons placed in solitary confinement from intense anxiety and sensory deprivation (Diamantis et al., 2020; North Simcoe Muskoka Specialized Geriatric Services, 2020).

One common concern regarding the mental health of LTC home residents during the COVID-19 pandemic is the increase in the use of psychoactive medications, which were frequently overprescribed prior to the pandemic (Abbasi, 2020; Rochon, 2007). A previous report documented increased prescribing of antipsychotics during the COVID-19 pandemic to people living with dementia in the United Kingdom (Howard et al., 2020). A population-based study of all Ontario LTC home residents found that prescribing of psychoactive drugs started in March 2020 during the onset of COVID-19 outbreaks and public health restrictions in LTC homes, which persisted through September 2020 (Figure 18). Increases in prescribing were out of proportion to expected trends over time, and distinct from observed prescribing changes in other drugs during the pandemic (Figure 17) (Stall, Zipursky, et al., 2020).

\section{Ontario Evidence to Support Public Health Interventions and Policy in LTC Homes}

The accumulating evidence on COVID-19 in Ontario's LTC homes has been leveraged in several ways to support public health interventions and policy during the pandemic. The early recognition in Ontario that SARSCoV-2 infections in LTC staff were associated with COVID-19 death among residents, and complementary evidence from other regions, motivated a public order implemented on April 22, 2020, restricting employees of LTC homes from working in more than one LTC home, congregate care, or healthcare setting within a 14-day period (Chen et al., 2020; Dunning et al., 2020; Fisman et al., 2020; McMichael et al., 2020).

An Ontario study examined the impact of this public policy by using anonymized mobile device location data to study the number of connections between all LTC homes during the seven weeks before and the seven weeks after the single-site work order (Jones et al., 2020). In the period preceding 


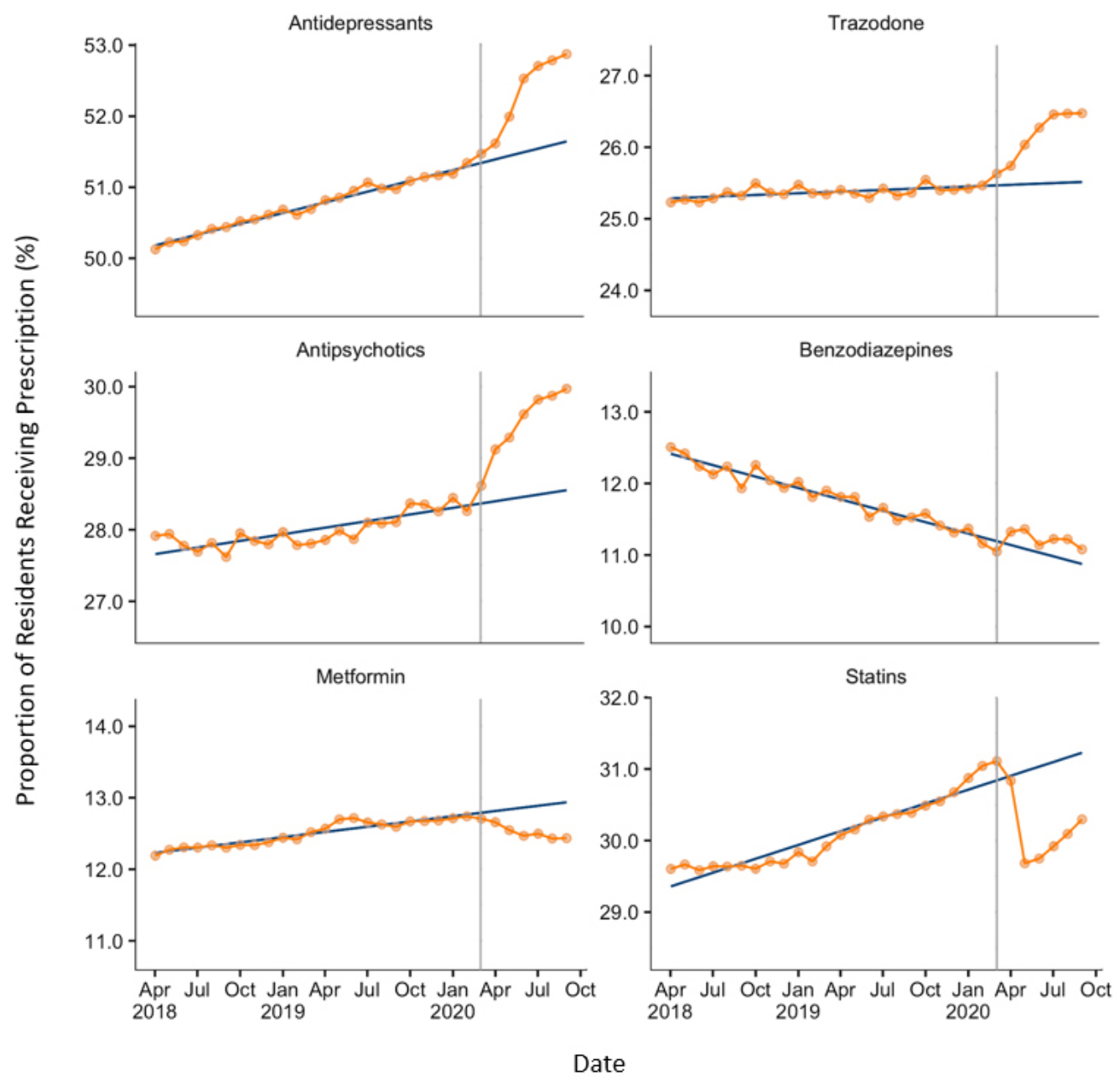

Figure 17. Prescription of Psychoactive Drugs to Ontario LTC Home Residents

Graphs presenting the monthly proportion of Ontario LTC home residents who were dispensed a prescription by psychoactive drug class, from April 2019 through September 2020. The grey vertical lines represent the beginning of the COVID-19 lockdown in Ontario in March 2020. The blue line represents expected monthly proportion of psychoactive prescriptions in Ontario LTC homes by drug class, based on the trends over time of each drug class in Ontario prior to the March 2020 lockdown. Figure adapted from Stall et al. JAMA Intern Med. 2020 (Stall et al., 2021).

the order, $42.7 \%$ (266) of LTC homes had a connection with at least one other home, compared to $12.7 \%$ (79) of homes during the period after restrictions, a drop of $70.3 \%(\mathrm{p}<0.001)$ (Figure 18). The average number of connections per home in the period before the order was 3.90, compared to 0.77 connections in the period after the order, a drop of $80.3 \%(\mathrm{p}<0.001)$. In both periods, mobility between LTC homes was higher in homes located in larger communities, those with higher bed counts, and those part of a large chain. 


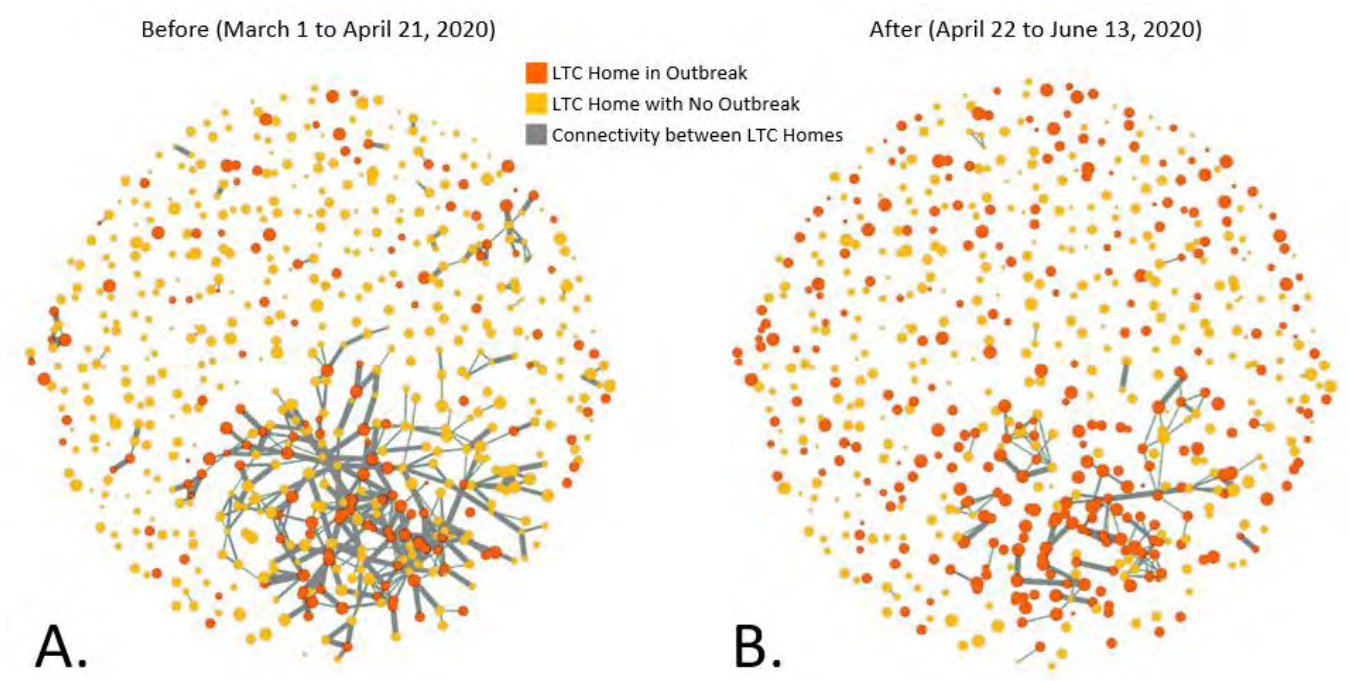

Figure 18. Network Connectivity of Ontario LTC Homes Before and After an Order Limiting Staff to Working in One LTC Home or Healthcare Setting within a 14-Day Period

Network connectivity diagrams presenting connectivity and outbreaks in Ontario LTC homes, from March 1 to June 13, 2020. Diagram A presents the period of 7 weeks before the implementation of an order which limited LTC homes staff from working in other LTC of healthcare settings within a 14-day period, from March 1 to April 21, 2020. Diagram B presents the period of 7 weeks after the implementation of the order, from April 22 to June 13, 2020. The grey lines represent connections between LTC homes, which thicker lines representing more connections, and thinner lines representing fewer connections. In the 7 weeks after the implementation of the order in Ontario (diagram B) there is a significant reduction in connectivity between homes, as compared to the 7 weeks prior to the implementation of the order in Ontario (diagram A). Figure adapted from Jones et al. J Am Med Dir Assoc. 2021 (Jones et al., 2021).

Documented risk factors for COVID-19 outbreaks, their size, and lethality, have been incorporated into provincial surveillance tools to identify and analyze higher risk LTC homes in the COVID-19 pandemic (Figure 19).

The findings associating crowding with SARS-CoV-2 infections and COVID-19 deaths in LTC homes motivated revisions to provincial directives on resident admissions to LTC homes (Brown, Jones, et al., 2020). A revision in June 2020 limited new resident admissions into rooms with more than two residents. In October 2020, it was further specified that "at any time, there should not be more than two (2) residents placed per room, including 3 or 4 bed ward rooms" (Government of Ontario, 2020).

Recognizing the need to balance IPAC measures in LTC homes with resident wellbeing, and following guidance from several organizations, the Province of Ontario moved to update its LTC home visitor policy in early September 2020 to give greater access to family caregivers (Canadian Foundation for 
If a home is in a community with more than 10 active cases per 100,000 inhabitants, the home is considered high risk, regardless of other criteria

- Community defined as a municipality

- COVID-19 case rate examined for overall community and non-LTC residents

Homes are also reviewed according to the following

four criteria to determine if they are high risk
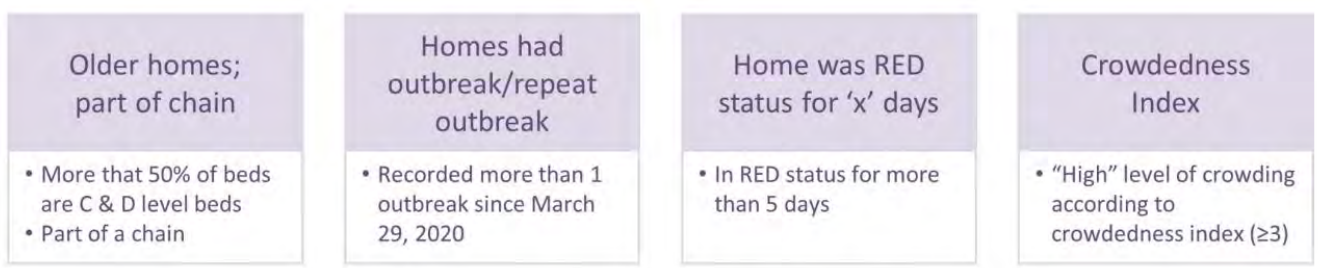

Figure 19. Application of Ontario LTC Home Data in Identifying and Analyzing Higher Risk Homes

Figure adapted from the Capacity Planning and Analytics Division, Ontario Ministry of Health (Ministry of Health and Long-Term Care, 2020).

Healthcare Improvement, 2020; Chu et al., 2020; Government of Ontario, 2020a; Long-Term Care Interest Group, 2020; RNAO, 2020; Stall, Johnstone, et al., 2020; Tupper et al., 2020)all public health agencies have been clear on one matter: older adults have the highest rates of mortality (Comas-Herrera et al., 2020. This allowed each resident and/or their substitute decision maker to designate a maximum of two caregivers who can visit a resident in LTC homes without time limits, including when a resident is infected with COVID-19 or when a LTC home is experiencing a COVID-19 outbreak (Ministry of Long Term Care, 2020). This policy aligns with emerging international evidence demonstrating the absence of evidence on the effectiveness of blanket visitor bans in reducing the introduction of SARS-CoV-2 infection in to LTC homes, and the relative safety of reintroducing family caregivers into LTC homes during the pandemic with appropriate IPAC procedures and access to PPE (Comas-Herrera, Salcher-Konrad, et al., 2020; Kruse et al., 2020; The National Collaborating Centre for Methods and Tools, 2020; Verbeek et al., 2020).

\section{Early Impact of the COVID-19 vaccine rollout on Ontario's LTC homes}

Ontario's COVID-19 vaccine rollout began in mid-December 2020, with LTC residents and staff identified as priority populations for vaccination. LTC home staff were the first to receive the vaccine in clinics starting on December 14, 2020. Most LTC home residents started receiving first doses of the COVID-19 vaccine after December 23, 2020. All 
LTC residents in Ontario were offered at least the first dose of a COVID-19 vaccine by February 13, 2021.

As of February 23, 2021, more than 64,000 Ontario LTC residents (92\%) received at least one dose of a COVID-19 vaccine, with over 46,500 residents having received both doses. Over 55,000 Ontario LTC staff (55\%) also received at least one dose of a COVID-19 vaccine, with more than 44,600 having received both doses.

As of February 23, 2021, COVID-19 vaccination in LTC homes prevented an estimated 2,079 SARSCoV-2 infections, 249 COVID-19 hos- pitalizations, and 615 COVID-19 deaths in residents, and an estimated 330 SARSCoV-2 infections, and 8 COVID-19 hospitalizations and 1 COVID-19 death in staff (Brown, Stall, et al., 2021).

Eight weeks after the start of vaccination, the estimated relative reduction in SARS-CoV-2 incidence was $89 \%$ in LTC residents and 79\% in LTC staff. The estimated relative reduction in COVID-19 mortality in LTC residents was $96 \%$ after 8 weeks. Overall, the rollout of COVID-19 vaccines in Ontario's LTC homes substantially reduced SARS-CoV-2 infections, COVID-19 hospitalizations, and deaths among LTC residents and staff (Figure 20).
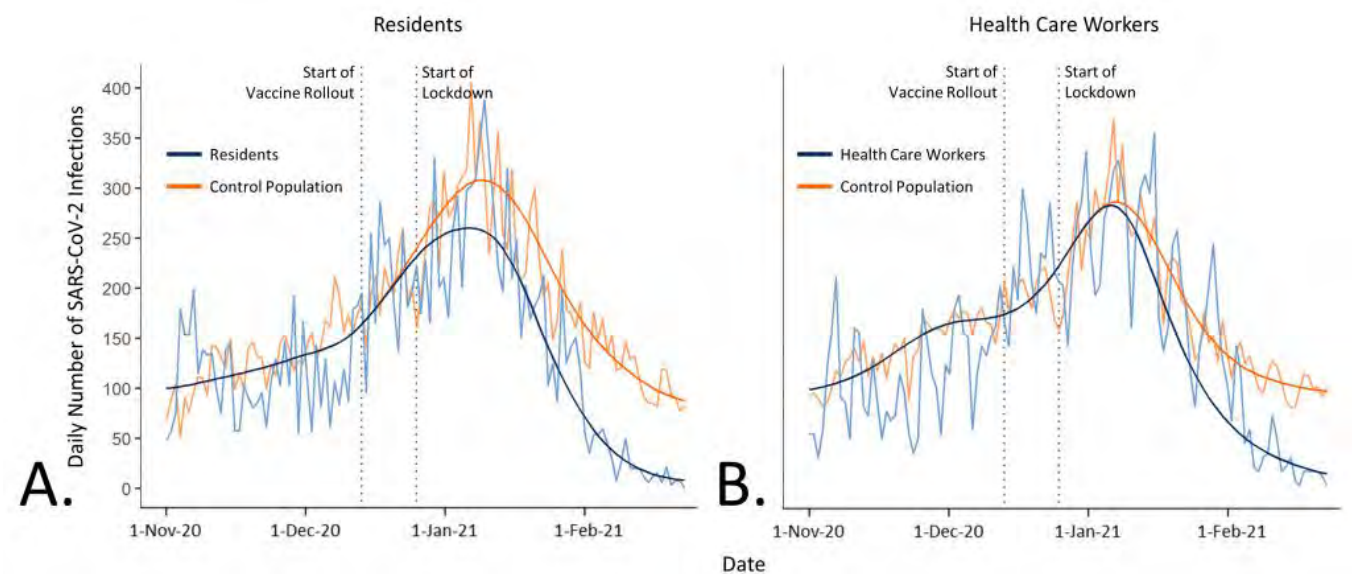

Figure 20. SARS-CoV-2 Infections Among Ontario LTC Residents and Staff from November 1, 2020, to February 23, 2021

Line graphs of daily numbers and fitted curves of SARS-CoV-2 infections among Ontario LTC residents and staff from November 1, 2020, to February 23, 2021. Panel A shows daily numbers and fitted curves of SARS-CoV-2 infections in LTC residents, and a control population of unvaccinated community-dwelling older adults aged 70 years or older. Panel B shows daily numbers and fitted curves of SARS-CoV-2 infections in LTC staff and a control population of unvaccinated working age adults 18-64 years of age. Daily numbers of SARS-CoV-2 infections are standardized and expressed as a percentage relative to the number of SARS-CoV-2 infections observed on November 1, 2020. In the absence of vaccination, LTC residents would have still benefited from the overall decline in the incidence of community SARS-CoV-2 infections, realized with tightened public health restrictions. However, observed incidence dropped substantially more with vaccination. Figure adapted from Brown et al. Sci Briefs Ont COVID-19 Sci Advis Table, 2021 (Brown, Stall, et al., 2021). 


\section{Interpretation}

7 he following are measures that could be effective in preventing COVID-19 outbreaks, hospitalizations, and deaths in Ontario's LTC homes (Box 1).

Box 1. Measures That Could Be Effective in Preventing COVID-19 Outbreaks, Hospitalizations, and Deaths in Ontario's LTC Homes

\section{Measures That Could Be Effective}

1. Promote staff entry and retention in the sector by improving the conditions of work

2. Prevent LTC worker infection with community tailored approaches

3. Further decrowd homes by continuing limits on occupancy and securing temporary housing

4. Detect LTC worker infection and prevent importation into LTC homes by prioritizing workers for testing and turnaround time, and by guaranteeing workers paid sick leave

5. Continue enhancing IPAC by securing one specialist per 200 beds in LTC homes

6. Pursue a more balanced and nuanced approach to public health measures and infection prevention in LTC homes

7. Implement strategies to expedite administration and improve vaccine acceptance in the LTC sector

8. Continue optimizing data on LTC homes for the duration of the COVID-19 pandemic

\section{Promote Staff Entry and Retention in the Sector by Improving the Conditions of Work}

The Ministry of Long-Term Care released a staffing study in July 2020 which emphasized that while the demand for LTC and resident acuity continues to increase in Ontario, staffing levels and access to appropriate training have not kept pace, resulting in a staffing crisis (Long-Term Care Staffing Study Advisory Group, 2020; Ng et al., 2020).
The LTC sector has had difficulty retaining staff because of extremely demanding job responsibilities, stressful and poor work conditions, negative public image about working in the sector, and a lack of full-time job opportunities with fair pay and benefits. As of 2018, there were 50,000 PSWs employed in Ontario's LTC sector sharing the equivalent of 32,700 full-time equivalent positions despite many staff wanting more full-time work (LongTerm Care Staffing Study Advisory 
Group, 2020). As a result, many PSWs need to work multiple part-time jobs to earn a living wage (Duan et al., 2020; Houtven et al., 2020; Long-Term Care Staffing Study Advisory Group, 2020).

The conditions of work within LTC homes and the difficulties in both promoting and retaining worker in the sector have been severely exacerbated by the COVID-19 pandemic (LongTerm Care Staffing Study Advisory Group, 2020). Many LTC home workers contracted SARS-CoV-2 infections themselves, with eight staff members dying of COVID-19 in the first wave and two staff members dying in the second wave to date. There is also a heightened fear among staff about onwards transmission of SARS-CoV-2 to family members, not having access to PPE given the shortages at the onset of the pandemic, and burnout given the stressful conditions many staff are exposed to in outbreak settings (Long-Term Care Staffing Study Advisory Group, 2020).

Addressing the longstanding staffing shortages is one of the most urgent issues confronting Ontario's LTC homes both during and in the wake of the COVID-19 pandemic (Boscart et al., 2018). Research from the United States highlights how homes with lower levels of staffing experienced a greater incidence of SARS-CoV-2 infections and COVID-19 mortality (Gorges \& Konetzka, 2020; Harrington et al., 2020).

Recent commitments from the Government of Ontario, including temporary pay increases for LTC workers, return of service incentives, accelerated training programs, and increased hours of care per resident are promising for promoting staff entry and retention. However, many of these enhancements are temporary and are unlikely to end the current reliance on temporary staffing (Government of Ontario, 2020c; Royal Society of Canada, 2020).

Ontario's LTC sector may benefit from extending these benefits beyond the COVID-19 pandemic, allowing the sector to minimize or eliminate staff mobility between homes and other workplaces during the COVID-19 pandemic. This could include creating more full-time jobs, more permanent pay increases, career ladders, and more immediate increases in the hours of care being provided to each resident. Recent pre-budget commitments to increasing staffing levels to provide four hours of direct care per resident by 2024-25 are encouraging, but no definitive staffing strategy or accompanying financial commitment has been made to date.

Some LTC experts have suggested ensuring that a minimum of $70 \%$ of LTC staff work full-time in a single site, with the remaining $30 \%$ being permanent, part-time staff, thereby allowing homes to have flexibility in staff scheduling. Such a plan would still need to ensure all full-time and part-time staff have fair pay and benefits including paid sick leave (Armstrong \& Cohen, 2020).

\section{Prevent LTC Worker Infection with Community Tailored Approaches}

As of 2018, approximately $90 \%$ of Ontario's PSW workforce was female and 
$41 \%$ were visible minorities. Many of these LTC home workers reside in neighbourhoods with lower socioeconomic status, increased household density, and a greater number of frontline workers; these are all neighbourhood characteristics that increase the risk of SARS-CoV-2 infection (Sundaram et al., 2020). Research from the United States documents a clear relationship between staff neighbourhood characteristics and COVID-19 LTC home outbreaks, and the same phenomenon is likely to exist in Ontario (Shen, 2020).

As our understanding of the COVID-19 pandemic has evolved, so too has our appreciation of the disproportionate impact the pandemic has incurred on under-served populations. There is now a greater recognition that a more robust community-based and tailored approach to public health measures is needed for individuals at higher risk of SARS-CoV-2 infection and burden of COVID-19, many of whom are frontline workers, racialized, living on low incomes, and who reside in crowded conditions (Alliance for Healthier Communities, 2020). Indeed, "one-size-fits-all" public health interventions, such as stay-at-home orders, are disproportionately difficult for marginalized individuals to comply with, rendering them both ineffective and inequitable (Alliance for Healthier Communities, 2020; Public Health Agency of Canada, 2020).

A broad range of community tailored approaches have been proposed, including recommendations from Canada's Chief Public Health Officer, such as: 1) enabling community health centres and local organizations to provide support and testing, 2) bottom-up approaches to gain and foster the trust of communities, including tailored communication and messaging, 3) individualized case management and support of households, and 4) top-down approaches at regional and provincial levels to support socioeconomically vulnerable households and communities (paid sick leave and eviction moratoriums).

The province of Ontario recently announced $\$ 12.5$ million in funding to support high priority communities, with community outreach, increased testing, and wraparound support (Government of Ontario, 2020d). Leveraging these community-tailored interventions specifically for more vulnerable LTC home staff would not only reduce existing inequities that place these individuals and their households at greater risk of COVID-19 infection, but could also reduce LTC home outbreaks.

\section{Further Decrowd Homes by Continuing Limits on Occupancy and Securing Temporary Housing}

The evidence from Ontario's first wave of COVID-19 clearly demonstrated that crowding in LTC homes was significantly associated with an increased incidence of resident SARS-CoV-2 infections and COVID-19 deaths (Brown, Jones, et al., 2020). Directives limiting admissions and occupancy to no more than two residents per room are sensi- 
ble, especially with financial commitments to fund homes as if they were at full capacity. However, these are hard to effectively and rapidly implement in case of existing high levels of occupancy. These directives are set to expire at the end of January 2021. Given the ongoing and extreme demand for LTC in Ontario, and the fact that many residents were already occupying these rooms, there are nearly 3,500 residents currently remaining in multi-occupancy rooms (Figure 19).

While additional funding may be required to financially protect homes when reducing occupancy in the sector, several measures to pre-emptively decrowd Ontario LTC homes may be effective. This includes creating temporary spaces such as field hospitals, using unoccupied hotels, and creating climate-controlled shelters in the parking lots or green spaces of LTC homes (Baughman et al., 2020). These spaces could also be used as part of outbreak management to temporarily relocate residents living in LTC homes with large COVID-19 outbreaks, which could both provide homes with additional space to isolate and cohort residents, and reduce some of the burden of caring for complex and high acuity residents in outbreak settings (Alliance for Healthier Communities, 2020; Stall, Farquharson, et al., 2020)with homes experiencing widespread outbreaks, resulting in severe morbidity and mortality among their residents. This article describes a 371-bed acutecare hospital's emergency response to a 126-bed nursing home experiencing a COVID-19 outbreak in Toronto,
Canada. Like other healthcare system responses to COVID-19 outbreaks in nursing homes, this hospital-nursing home partnership can be characterized in several phases: (1. The recently opened Specialized Care Centre in the Greater Toronto Area now has the capacity for 30 LTC residents to be temporarily relocated for ongoing care for homes experiencing large outbreaks and staffing challenges (Government of Ontario, 2020e).

Finally, while existing efforts to reduce crowding are necessary to prevent resident SARS-CoV-2 infections and COVID-19 deaths, these efforts resulted in a decreased number of available LTC beds and an increased LTC waiting list, which now stands at over 39,000 Ontarians. Longer-term commitments to build 30,000 new LTC beds in Ontario will not assist with this in the short-term. More home care supports for the increasing number of individuals waiting for LTC placement in the community is essential to avoid increasing the number of alternate levels of care (ALC) patients, especially as many hospitals are near, at, or above capacity during the second wave.

The recent government commitments to make greater investments in the provision of more home and community care and expanded community paramedicine programs to support LTC waitlisted individuals is promising, and other options to consider are innovative proposals like a virtual LTC program (National Institute for Ageing, 2020). 
Detect LTC Worker Infection and

Prevent Importation into LTC

Homes by Prioritizing Workers

for Testing, and by Guaranteeing

Workers Paid Sick Leave

As community transmission of SARS$\mathrm{CoV}-2$ increases, there is a predictable increase in SARS-CoV-2 infections among LTC staff, necessitating strategies to both prevent and detect community and staff infections before they are imported in to LTC homes.

As previously discussed, many LTC home staff have part-time jobs without access to paid sick leave, meaning that staff may come to work sick and/or they may be forced to work other front-facing jobs that increase their risk of SARS-CoV-2 infection. More immediate and long-term commitments to increasing the number of full-time jobs with fair pay and benefits including paid sick leave will help remedy the staffing crisis and can also help reduce transmission of SARS-CoV-2 into LTC homes (Rios et al., 2020).

It also remains important that LTC residents and staff continue to be prioritized for timely COVID-19 testing with a short turnaround time of results (McGarry et al., 2020). Modeling suggests that frequent serial testing (e.g., 2-3 times weekly) of staff may be effective in reducing outbreaks if test turnaround time is rapid. However, the feasibility of such frequent testing is unclear with Ontario's current testing system, and this strategy may be insufficiently effective with surging community SARSCoV-2 transmission (Chin et al., 2020).
Rapid antigen-based COVID-19 testing for staff is being employed in a select number of homes, but there are concerns about suboptimal test performance in the high-risk LTC setting, including higher rates of false positives, which could further exacerbate existing staffing shortages. Furthermore, the health human resources a home would require to implement twice or thrice weekly testing is substantial (Kain et al., 2021). Finally, staff "bubbling," when staff confine themselves to a LTC home along with residents, has been implemented with documented success in reducing COVID-19 outbreaks in jurisdictions such as France. However, this approach seems impractical for most Ontario LTC homes (Belmin et al., 2020).

\section{Continue Enhancing Infection}

Prevention and Control (IPAC) by Securing One Specialist per 200 Beds in LTC Homes

IPAC processes have improved in some of Ontario's LTC homes since the onset of the pandemic, especially with implementation of the "hub and spoke" model, in which staff are being trained and managed by IPAC specialists of nearby acute care hospitals (Elrod \& Fortenberry, 2017). There is still ongoing and urgent need for increased IPAC staffing, including commitments to hiring infection control staff at a ratio of one specialist per 200 beds in a LTC home, which has been recommended by the Provincial Infectious Diseases Advisory Committee (PIDAC) best practice guidance document since the 2003 
SARS-CoV-1 outbreak in Toronto (Ontario Agency for Health Protection and Promotion et al., 2012).

It remains clear that an inadequate understanding of IPAC practice, and an inadequate implementation of IPAC measures in LTC homes relative to acute care hospitals means that outbreaks are controlled rapidly in acute care, but are persistent and devastating in LTC settings. While practice improvements have reduced the risk of SARS-CoV-2 transmission in the second wave, as compared to the first wave in Ontario's LTC sector, the risk of on-going transmission in LTC outbreaks is still substantial. Continued improvement in IPAC practice is key to protecting residents, staff, and essential caregivers from COVID-19.

\section{Pursue a More Balanced and Nuanced Approach to Public Health Measures and Infection Prevention in LTC Homes}

The greatest risk factor for whether a home will experience an outbreak is the incidence of SARS-CoV-2 and COVID-19 in the communities surrounding LTC homes. As such, the protection of LTC residents begins with maximal suppression of SARS-CoV-2 transmission in the community. While some have proposed targeted isolation of the vulnerable LTC population, it is practically impossible to restrict outbreaks and transmission in particular subpopulations while allowing widespread transmission of SARS-CoV-2 in the general population (Alwan et al., 2020). Furthermore, targeted iso- lation of a population is unethical and risks further exacerbating inequities and structural discrimination that are already present in LTC settings (Ganguli-Mitra et al., 2020).

Building on the province's updated visitor guidelines that permitted caregivers back in to LTC homes in September 2020, there is an opportunity to balance and nuance infection prevention and public health measures in Ontario LTC homes. This will keep residents protected from COVID-19 and maintain their health and wellbeing throughout the remainder of the pandemic. Adequate practice and support for practice among essential family caregivers is critical in order to prevent the propagation of outbreaks in LTC homes.

One particularly challenging transition for LTC residents is new admission to a LTC home, since change in a familiar environment can be distressing for residents, especially when nearly $70 \%$ live with dementia and almost $90 \%$ have some form of cognitive impairment (Canadian Institute for Health Information, 2020a). Earlier in the pandemic, new admissions to Ontario LTC homes currently require 14days of self-isolation under Droplet and Contact Precautions with a negative SARS-CoV-2 test result at the end of self-isolation (Government of Ontario, 2020). This precautionary approach was sensible from an IPAC perspective, but could precipitate substantial distress in newly admitted residents who had not yet acclimatized to their new environments. Additional resources and atten- 
tion should be paid to preventing and mitigating the behavioural and psychological risks of this self-isolation period if it is reinstituted in successive waves of the pandemic. This could include implementing strategies in LTC homes that better maintain the dignity and psychological wellbeing of the person requiring self-isolation (Iaboni, Cockburn, et al., 2020; Iaboni, Grigorovich, et al., 2020).

Furthermore, in communities surrounding LTC homes that were identified as "high risk," most shortterm absences were also suspended earlier the pandemic, resulting in the inability of most residents to leave the property of a LTC home. While this intervention was likely intended to prevent LTC home residents from entering high-risk transmission settings in the community, it also had the effect of preventing residents from going outside for fresh air or on short walks in the immediate vicinity of LTC homes; more recent updates to provincial policies have reinstated both short-term and overnight absences.

\section{Implementing Strategies to Improve Vaccine Acceptance in the LTC Sector}

As of July 12, 2021, over 72,000 LTC residents received at least one dose of a COVID-19 vaccine (106\%) with $>69,000$ having received both doses. Over 89,000 LTC staff have also received at least one dose of a COVID-19 vaccine (93\%), with $>84,000$ having received both doses.
To improve vaccine acceptance, the LTC sector and its clinicians should be supported with educational materials and recommended behavioural change strategies to confidence in COVID-19 vaccines. One particularly important initiative will be improving vaccine acceptance among Ontario LTC staff, whose influenza vaccination uptake was $76.4 \%$ in 2019-2020 (Jaklevic, 2020; Public Health Ontario, 2020b). Strategies to promote vaccine acceptance among LTC homes include: hearing, validating, and addressing staff concerns about the COVID-19 vaccine development process, approval and safety; identifying peer champions to educate and encourage fellow staff vaccination; and by providing education and ongoing communication about COVID-19 vaccination programs (Finney Rutten et al., 2020; French et al., 2020). Finances and logistics may pose additional barriers to staff vaccination because of transportation and parking costs, and unpaid time away from work both while going to get vaccinated and in case of vaccine side effects causing missed work (Volpp et al., 2021)this important milestone is only the first step in an equally important challenge: getting a majority of the US public vaccinated. In a September 2020 survey of 10093 US adults, only $51 \%$ indicated that they were definitely or probably willing to be vaccinated with a novel COVID-19 vaccine, $25 \%$ reported that they were probably not willing to get the vaccine, and $24 \%$ reported that it is unlikely that they would be vaccinated. This survey further revealed that acceptance was lower among Black individuals (32\%, 263 of 822). 
Continue Optimizing Data on LTC Homes for the Duration of the COVID-19 Pandemic

Rapid collection and access to data on the COVID-19 pandemic in Ontario's LTC homes has generated substantial knowledge that has already been translated into public health policy. It is essential that Ontario continues to optimize sources of data on the LTC sector for the duration of the COVID-19 pandemic and beyond. This includes resuming expedited reviews of all COVID-19 and non-COVID-19 deaths occurring in LTC homes throughout the remainder of the pandemic, which stopped on June 29, 2020. This will facilitate ongoing calculations of excess mortality in the sector. Additionally, timely and complete data on vaccination rates among LTC residents, staff and essentially family caregivers is critical to understanding the success and effectiveness of Ontario's COVID-19 vaccine rollout.

It is also essential that the LTC sector provide additional resources to LTC homes to promote timely and complete Resident Assessment Instrument - Minimum Data Set 2.0 (RAIMDS 2.0) data collection on all residents (Kim et al., 2015; Mor, 2004). This data is essential in understanding how the functional and psychosocial status and care needs of Ontario's LTC residents have been and continue to be impacted by the COVID-19 pandemic (McArthur et al., 2021). The RAI-MDS 2.0 is normally completed on admission to a LTC home, quarterly, and after any substantial health change.
Given the more limited feasibility of completing the RAI-MDS 2.0 during a pandemic, Ontario should prioritize the implementation of the next generation assessment, the interRAI LTCF, which is supported by CIHI and has been implemented in New Brunswick and internationally (Hirdes et al., 2008; interRAI, 2020).

Given the uncertainty some homes have in allowing essential family caregivers and visitors to regularly access homes, and to allow residents to leave on short absences, it is important to collect data on the frequency and nature of these occurrences to both understand the risks they may or may not carry with respect to SARS-CoV-2 transmission and the impact they have on resident quality of life and wellbeing.

Finally, enhancing data on staffing may be effective in increasing the understanding of levels and hours of care being provided to residents in LTC homes as well as the risk of staff being infected with COVID-19 and subsequently importing COVID-19 into LTC homes. This data could help support community tailored approaches specifically focused on LTC home workers.

The COVID-19 pandemic has had a devastating impact on Ontario's LTC sector. A large body of evidence now documents the predictors of COVID-19 outbreaks, SARS-CoV-2 transmission, and deaths in Ontario's LTC homes. While some of the existing evidence has been effectively leveraged to support public health interventions 
and policies, there are additional measures that may be effective in preventing COVID-19 outbreaks and deaths within LTC homes during both the pre- and post-COVID-19 vaccine era.

\section{Author Contributions}

NS wrote the first draft of the science brief. All authors contributed to the conception of the science brief, revised it critically for important intellectual content, and approved the final version.

\section{References}

Abbasi, J. (2020). Social isolation-The other COVID-19 threat in nursing homes. JAMA, 324(7), 619. https://doi.org/10.1001/jama.2020.13484

Alliance for Healthier Communities. (2020, November 17). To effectively support marginalized people most impacted by COVID-19, Ontario needs a community response strategy. https://www.allianceon.org/blog/effectively-support-marginalized-people-most-impacted-COVID-19-Ontarioneeds-community-response

Alwan, N. A., Burgess, R. A., Ashworth, S., Beale, R., Bhadelia, N., Bogaert, D., Dowd, J., Eckerle, I., Goldman, L. R., Greenhalgh, T., Gurdasani, D., Hamdy, A., Hanage, W. P., Hodcroft, E. B., Hyde, Z., Kellam, P., Kelly-Irving, M., Krammer, F., Lipsitch, M., ... Ziauddeen, H. (2020). Scientific consensus on the COVID-19 pandemic: We need to act now. The Lancet, 396(10260), e71-e72. https://doi.org/10.1016/S0140-6736(20)32153-X

Armstrong, P., \& Cohen, M. (2020). A higher standard: Setting federal standards in long-term care and continuing care. Canadian Cantre for Policy Alternatives. https://www.policyalternatives.ca/sites/default/files/uploads/pub lications/National\%20Office/2020/11/A\%20higher\%20standard.pdf

Arons, M. M., Hatfield, K. M., Reddy, S. C., Kimball, A., James, A., Jacobs, J. R., Taylor, J., Spicer, K., Bardossy, A. C., Oakley, L. P., Tanwar, S., Dyal, J. W., Harney, J., Chisty, Z., Bell, J. M., Methner, M., Paul, P., Carlson, C. M., McLaughlin, H. P., ... Jernigan, J. A. (2020). Presymptomatic SARS-CoV-2 infections and transmission in a skilled nursing facility. New England Journal of Medicine, 382(22), 2081-2090. https://doi.org/10.1056/NEJMoa2008457

Baughman, A. W., Hirschberg, R. E., Lucas, L. J., Suarez, E. D., Stockmann, D., Johnson, S. H., Hutter, M. M., Murphy, D. J., Marsh, R. H., Thompson, R. W., Boland, G. W., Erickson, J. I., \& Palamara, K. (2020). Pandemic care through collaboration: Lessons from a COVID-19 field hospital. Journal of the American Medical Directors Association, 21(11), 1563-1567. https:// doi.org/10.1016/j.jamda.2020.09.003 
Belmin, J., Um-Din, N., Donadio, C., Magri, M., Nghiem, Q. D., Oquendo, B., Pariel, S., \& Lafuente-Lafuente, C. (2020). Coronavirus disease 2019 outcomes in french nursing homes that implemented staff confinement with residents. JAMA Network Open, 3(8), e2017533. https://doi.org/10.1001/ jamanetworkopen.2020.17533

Block, S., \& Dhunna, S. (2020). What does it cost to care? (p. 12). Canadian Centre for Policy Alternatives. https://www.policyalternatives.ca/sites/default/ files/uploads/publications/Ontario $\% 20$ Office/2020/06/Improving $\% 20$ care\%20in\%20Ontario\%20LTC\%20facilities_final.pdf

Boscart, V. M., Sidani, S., Poss, J., Davey, M., d’Avernas, J., Brown, P., Heckman, G., Ploeg, J., \& Costa, A. P. (2018). The associations between staffing hours and quality of care indicators in long-term care. BMC Health Services Research, 18(1), 750. https://doi.org/10.1186/s12913-018-3552-5

Brown, K. A., Daneman, N., Buchan, S. A., Chan, A. K., \& Stall, N. M. (2020). Temporal variations in the intensity of care provided to community and nursing home residents who died of COVID-19 in Ontario, Canada. MedRxiv, 2020.11.06.20227140. https://doi.org/10.1101/2020.11.06.20227140

Brown, K. A., Daneman, N., Buchan, S. A., Chan, A. K., \& Stall, N. M. (2021). Variation in Care of Community and Nursing Home Residents Who Died of COVID-19 in Ontario, Canada. Journal of the American Medical Directors Association, 22(6), 1149-1150. https://doi.org/10.1016/j.jam da.2021.04.008

Brown, K. A., Jones, A., Daneman, N., Chan, A. K., Schwartz, K. L., Garber, G. E., Costa, A. P., \& Stall, N. M. (2020). Association between nursing home crowding and COVID-19 infection and mortality in Ontario, Canada. JAMA Internal Medicine. https://doi.org/10.1001/jamainternmed.2020.6466

Brown, K. A., Stall, N. M., Vanniyasingam, T., Buchan, S. A., Daneman, N., Hillmer, M. P., Hopkins, J., Johnstone, J., Maltsev, A., McGeer, A. J., Sander, B., Savage, R. D., Watts, T., Juni, P., \& Rochon, P. A. (2021). Early impact of Ontario's COVID-19 vaccine rollout on long-term care home residents and health care workers. Science Briefs of the Ontario COVID-19 Science Advisory Table, 2(13). https://doi.org/10.47326/ocsat.2021.02.13.1.0

Cagnin, A., Di Lorenzo, R., Marra, C., Bonanni, L., Cupidi, C., Laganà, V., Rubino, E., Vacca, A., Provero, P., Isella, V., Vanacore, N., Agosta, F., Appollonio, I., Caffarra, P., Pettenuzzo, I., Sambati, R., Quaranta, D., Guglielmi, V., Logroscino, G., ... Bergamelli, C. (2020). Behavioral and psychological effects of coronavirus disease-19 quarantine in patients with dementia. Frontiers in Psychiatry, 11. https://doi.org/10.3389/fpsyt.2020.578015 
Canadian Foundation for Healthcare Improvement. (2020). Better together: E-integration offamily caregivers as essential partners in care in a time ofCOVID-19. https://www.cfhi-fcass.ca/docs/default-source/itr/tools-and-resources/ bt-re-integration-of-family-caregivers-as-essential-partners-covid-19-e. pdf?sfvrsn $=5 \mathrm{~b} 3 \mathrm{~d} 8 \mathrm{f} 3 \mathrm{~d} \_2$

Canadian Institute for Health Information. (2020a). Dementia in long-term care. Journal of Nursing Management. https://www.cihi.ca/en/dementia-in-can ada/dementia-care-across-the-health-system/dementia-in-long-termcarehttps://www.cihi.ca/en/dementia-in-canada/dementia-care-acrossthe-health-system/dementia-in-long-term-care

Canadian Institute for Health Information. (2020b). Pandemic experience in the long-term care sector: How does Canada compare with other countries? Canadian Institut for Health Information. https://www.cihi.ca/sites/default/ files/document/covid-19-rapid-response-long-term-care-snapshot-en.pdf

Canadian Institute for Health Information. (2020c, September 24). Long-term care homes in Canada: How many and who owns them? Cihi.Ca. https://www. cihi.ca/en/long-term-care-homes-in-canada-how-many-and-who-ownsthem

Chen, M. K., Chevalier, J. A., \& Long, E. F. (2020). Nursing home staff networks and COVID-19. National Bureau of Economic Research, 28. https://doi. $\operatorname{org} / 10.3386 / \mathrm{w} 27608$

Chin, E. T., Huynh, B. Q., Chapman, L. A., Murrill, M., Basu, S., \& Lo, N. C. (2020). Frequency of routine testing for COVID-19 in high-risk environments to reduce workplace outbreaks. MedRxiv, 2020.04.30.20087015. https://doi. org/10.1101/2020.04.30.20087015

Chow, E. J., Schwartz, N. G., Tobolowsky, F. A., Zacks, R. L. T., Huntington-Frazier, M., Reddy, S. C., \& Rao, A. K. (2020). Symptom screening at Illness onset of health care personnel with SARS-CoV-2 infection in King County, Washington. JAMA, 323(20), 2087. https://doi.org/10.1001/jama.2020.6637

Chu, C. H., Donato-Woodger, S., \& Dainton, C. J. (2020). Competing crises: COVID-19 countermeasures and social isolation among older adults in long-term care. Journal of Advanced Nursing, 76(10), 2456-2459. https:// doi.org/10.1111/jan.14467

Comas-Herrera, A., Salcher-Konrad, M., Baumbusch, J., Farina, N., Goodman, C., $\&$ Lorenz-Dant, K. (2020). Rapid review of the evidence on impacts of visiting policies in care homes during the COVID-19 pandemic (p. 6). McMaster University. https://www.nccmt.ca/uploads/media/media/0001/02/3021cb 8ca67e86dfa1d29ea5ef2ea14dc486bfe1.pdf 
Comas-Herrera, A., Zalakaín, J., Litwin, C., Hsu, A. T., Lemmon, E., Henderson, D., \& Fernández, J.-L. (2020). Mortality associated with COVID-19 outbreaks in care homes: Early international evidence (p. 28). International Long-Term Care Policy Network. https://tccovid.org/wp-content/up loads/2020/06/Mortality-associated-with-COVID-among-people-whouse-long-term-care-26-June-1.pdf

Committee on Family Caregiving for Older Adults, Board on Health Care Services, Health and Medicine Division, \& National Academies of Sciences, Engineering, and Medicine. (2016). Families Caring for an Aging America (R. Schulz \& J. Eden, Eds.). National Academies Press (US). http://www. ncbi.nlm.nih.gov/books/NBK396401/

North Simcoe Muskoka Specialized Geriatric Services. (2020). Confinement syndrome. North Simcoe Muskoka Specialized Geriatric Services. https:// www.nsmsgs.ca/Uploads/ContentDocuments/Confinement\%20Syn drome\%20Aug17-20.pdf

Government of Ontario. (2020, November 20). COVID-19: Long-term care homes in areas with visitor restrictions. Ontario.Ca. https://www.ontario.ca/page/ covid-19-long-term-care-homes-in-areas-visitor-restrictions

Diamantis, S., Noel, C., Tarteret, P., Vignier, N., \& Gallien, S. (2020). Severe Acute Respiratory Syndrome Coronavirus 2 (SARS-CoV-2)-related deaths in french long-term care facilities: The "Confinement Disease" is probably more deleterious than the coronavirus disease-2019 (COVID-19) itself. Journal of the American Medical Directors Association, 21(7), 989-990. https://doi.org/10.1016/j.jamda.2020.04.023

Government of Ontario. (2020). Directive \#3 update: Long-term care visitors and admissions. Ontario Ministries of Health and Long-Term Care. http:// health.gov.on.ca/en/pro/programs/publichealth/coronavirus/docs/direc tives/LTCH_HPPA.pdf

Duan, Y., Iaconi, A., Song, Y., Norton, P. G., Squires, J. E., Keefe, J., Cummings, G. G., \& Estabrooks, C. A. (2020). Care Aides Working Multiple Jobs: Considerations for Staffing Policies in Long-Term Care Homes During and After the COVID-19 Pandemic. Journal of the American Medical Directors Association, 21(10), 1390-1391. https://doi.org/10.1016/j.jamda.2020.07.036

Dunning, J., Dhuper, M., \& Sinha, S. (2020). The NIA's 'Iron Ring' guidance for protecting older canadians in long-term care and congregate living settings. National Institute on Ageing. https://staticl.squarespace.com/static/5c 2fa7b03917eed9b5a436d8/t/5f0f4610bcc2c332db002e67/1594836496177/ NIA+Iron+Ring+Guidance+Document+July+15_2020.pdf 
Elrod, J. K., \& Fortenberry, J. L. (2017). The hub-and-spoke organization design: An avenue for serving patients well. BMC Health Services Research, 17(1), 457. https://doi.org/10.1186/s12913-017-2341-x

Finney Rutten, L. J., Zhu, X., Leppin, A., Ridgeway, J. L., Swift, M., Griffin, J. M., St Sauver, J. L., Virk, A., \& Jacobson, R. M. (2020). Evidence-based strategies for clinical organizations to address COVID-19 vaccine hesitancy. Mayo Clinic Proceedings, S0025619620314877. https://doi.org/10.1016/j.mayo cp.2020.12.024

Fisman, D. N., Bogoch, I., Lapointe-Shaw, L., McCready, J., \& Tuite, A. R. (2020). Risk factors associated with mortality among residents with coronavirus disease 2019 (COVID-19) in long-term care facilities in Ontario, Canada. JAMA Network Open, 3(7), e2015957. https://doi.org/10.1001/jamanet workopen.2020.15957

French, J., Deshpande, S., Evans, W., \& Obregon, R. (2020). Key guidelines in developing a pre-emptive COVID-19 vaccination uptake promotion strategy. International Journal of Environmental Research and Public Health, 17(16). https://doi.org/10.3390/ijerph17165893

Ganguli-Mitra, A., Young, I., Engelmann, L., Harper, I., McCormack, D., Marsland, R., Buch Segal, L., Sethi, N., Stewart, E., \& Tichenor, M. (2020). Segmenting communities as public health strategy: A view from the social sciences and humanities. Wellcome Open Research, 5, 104. https://doi.org/10.12688/ wellcomeopenres.15975.1

Goldberg, S. A., Lennerz, J., Klompas, M., Mark, E., Pierce, V. M., Thompson, R. W., Pu, C. T., Ritterhouse, L. L., Dighe, A., Rosenberg, E. S., \& Grabowski, D. C. (2020). Presymptomatic transmission of Severe Acute Respiratory Syndrome Coronavirus 2 among residents and staff at a skilled nursing facility: Results of real-time Polymerase Chain Reaction and serologic testing. Clinical Infectious Diseases, ciaa991. https://doi.org/10.1093/cid/ ciaa991

Gorges, R. J., \& Konetzka, R. T. (2020). Staffing levels and COVID-19 cases and outbreaks in U.S. nursing homes. Journal of the American Geriatrics Society, 68(11), 2462-2466. https://doi.org/10.1111/jgs.16787

Government of Canada. (2020a, July 17). Interim guidance: Care of residents in long term care homes during the COVID-19 pandemic. https://www.canada. ca/en/public-health/services/diseases/2019-novel-coronavirus-infection/ guidance-documents/residents-long-term-care-homes-covid-19.html

Government of Canada. (2020b, September 29). Population estimates on July 1st, by age and sex. Statistics Canada. https://www150.statcan.gc.ca/t1/tbl1/en/ tv.action?pid=1710000501 
Government of Ontario. (2014, July 24). O. reg. 146/20: Limiting work to a single long-term care home. Ontario.Ca. https://www.ontario.ca/laws/view

Government of Ontario. (2020a, September 2). Welcoming caregivers to Ontario's long-term care homes. Ontario Newsroom. https://news.ontario.ca/en/re lease/58220/welcoming-caregivers-to-ontarios-long-term-care-homes

Government of Ontario. (2020b, November 3). COVID-19 response framework: Keeping Ontario safe and open. Ontario.Ca. https://www.ontario.ca/page/ covid-19-response-framework-keeping-ontario-safe-and-open

Government of Ontario. (2020c, December 16). A better place to live, a better place to work: Ontario's long-term care staffing plan. Ontario.Ca. https://www. ontario.ca/page/better-place-live-better-place-work-ontarios-long-termcare-staffing-plan

Government of Ontario. (2020d, December 21). Ontario supporting high priority communities. Ontario Newsroom. https://news.ontario.ca/en/background er/59793/ontario-supporting-high-priority-communities

Government of Ontario. (2020e, December 28). Ontario opening specialized care centre in Greater Toronto Area. Ontario Newsroom. https://news.ontario. ca/en/release/59829/ontario-opening-specialized-care-centre-in-great er-toronto-area

Hado, E., \& Feinberg, L. F. (2020). Amid the COVID-19 pandemic, meaningful communication between family caregivers and residents of long-term care facilities is imperative. Journal of Aging \& Social Policy, 32(4-5), 410-415. https://doi.org/10.1080/08959420.2020.1765684

Harrington, C., Ross, L., Chapman, S., Halifax, E., Spurlock, B., \& Bakerjian, D. (2020). Nurse staffing and coronavirus infections in California nursing homes. Policy, Politics, \& Nursing Practice, 21(3), 174-186. https://doi. org/10.1177/1527154420938707

Hirdes, J. P., Ljunggren, G., Morris, J. N., Frijters, D. H., Finne Soveri, H., Gray, L., Björkgren, M., \& Gilgen, R. (2008). Reliability of the interRAI suite of assessment instruments: A 12-country study of an integrated health information system. BMC Health Services Research, 8(1), 277. https://doi. org/10.1186/1472-6963-8-277

Houtven, C. H. V., DePasquale, N., \& Coe, N. B. (2020). Essential long-term care workers commonly hold second jobs and double- or triple-duty caregiving roles. Journal of the American Geriatrics Society, 68(8), 1657-1660. https:// doi.org/10.1111/jgs.16509

Howard, R., Burns, A., \& Schneider, L. (2020). Antipsychotic prescribing to peo- 
ple with dementia during COVID-19. The Lancet Neurology, 19(11), 892. https://doi.org/10.1016/S1474-4422(20)30370-7

Hoxha, A., Wyndham-Thomas, C., Klamer, S., Dubourg, D., Vermeulen, M., Hammami, N., \& Cornelissen, L. (2020). Asymptomatic SARS-CoV-2 infection in Belgian long-term care facilities. The Lancet Infectious Diseases, S1473309920305600. https://doi.org/10.1016/S1473-3099(20)30560-0

Iaboni, A., Cockburn, A., Marcil, M., Rodrigues, K., Marshall, C., Garcia, M. A., Quirt, H., Reynolds, K. B., Keren, R., \& Flint, A. J. (2020). Achieving safe, effective, and compassionate quarantine or isolation of older adults with dementia in nursing homes. The American Journal of Geriatric Psychiatry, 28(8), 835-838. https://doi.org/10.1016/j.jagp.2020.04.025

Iaboni, A., Grigorovich, A., Barned, C., Rodrigues, K., Kontos, P., Chu, C., \& Astell, A. (2020). Dementia Isolation Toolkit (p. 38). https://dementiaisolationtoolkit.com/wp-content/uploads/2020/09/Dementia-Isolation-Tool kit-Full-1.pdf

interRAI. (2020). Long-term care facilities (LTCF). Interrai.Org. https://www.interrai.org/long-term-care-facilities.html

Jaklevic, M. C. (2020). Nursing homes' next test-Vaccinating workers against COVID-19. JAMA, 324(19), 1928. https://doi.org/10.1001/ jama.2020.21354

Jones, A., Watts, A. G., Khan, S. U., Forsyth, J., Brown, K. A., Costa, A. P., Bogoch, I. I., \& Stall, N. M. (2020). Impact of a public policy restricting staff mobility between long-term care homes in Ontario, Canada during the COVID-19 pandemic. MedRxiv, 2020.11.17.20231498. https://doi. org/10.1101/2020.11.17.20231498

Jones, A., Watts, A. G., Khan, S. U., Forsyth, J., Brown, K. A., Costa, A. P., Bogoch, I. I., \& Stall, N. M. (2021). Impact of a Public Policy Restricting Staff Mobility Between Nursing Homes in Ontario, Canada During the COVID-19 Pandemic. Journal of the American Medical Directors Association, 22(3), 494-497. https://doi.org/10.1016/j.jamda.2021.01.068

Jüni, P., Odutayo, A., Allen, U., Fisman, D. N., Hayes, A., Manuel, D. G., Munshi, L., Razak, F., Sander, B., \& Slutsky, A. S. (2020). Dexamethasone in patients hospitalized for COVID-19. Science Briefs of the Ontario COVID-19 Science Advisory Table, 1(1). https://doi.org/10.47326/ocsat.2020.01.01.1.0

Kain, D., Stall, N. M., Allen, V., Evans, G. A., Hopkins, J., Kouyoumdjian, F. G., McGeer, A., Mubareka, S., Patel, S. N., Rochon, P. A., Schwartz, B., Juni, P., \& Johnstone, J. (2021). Routine asymptomatic SARS-CoV-2 screen test- 
ing of staff in Ontario long-term care homes. Science Briefs of the Ontario COVID-19 Science Advisory Table, 2(15). https://doi.org/10.47326/ocsat.2021.02.15.1.0

Kim, H., Jung, Y.-I., Sung, M., Lee, J.-Y., Yoon, J.-Y., \& Yoon, J.-L. (2015). Reliability of the interRAI Long Term Care Facilities (LTCF) and interRAI Home Care (HC). Geriatrics \& Gerontology International, 15(2), 220-228. https:// doi.org/10.1111/ggi.12330

Kruse, F., Vrinzen, C., Jeurissen, P., van der Woerd, O., \& van Tol, L. (2020). The impact of COVID-19 on long-term care in the Netherlands: The second wave. 24.

Liu, M., Maxwell, C. J., Armstrong, P., Schwandt, M., Moser, A., McGregor, M. J., Bronskill, S. E., \& Dhalla, I. A. (2020). COVID-19 in long-term care homes in Ontario and British Columbia. CMAJ, 192(47), E1540-E1546. https:// doi.org/10.1503/cmaj.201860

Long-Term Care Interest Group. (2020). Family presence in older adult care a statement regarding family caregivers and the provision of essential care. https:// rgps.on.ca/wp-content/uploads/2020/06/2020-June-29-Family-Presencein-Older-Adult-Care-Family-Caregivers-FINAL.pdf

Long-Term Care Staffing Study Advisory Group. (2020). Long-term care staffing study (p. 51). Ministry of Long-Term Care. https://files.ontario.ca/mltclong-term-care-staffing-study-en-2020-07-31.pdf

Low, L.-F. (2020, May 13). Easing lockdowns in care homes during COVID-19: Risks and risk reduction. Ltccovid.Org. https://tccovid.org/2020/05/13/easinglockdowns-in-care-homes-during-covid-19-risks-and-risk-reduction/

Malikov, K., Huang, Q., Shi, S., Stall, N. M., Tuite, A. R., \& Hillmer, M. P.(2020). Temporal associations between community incidence of COVID-19 and nursing home outbreaks in Ontario, Canada. MedRxiv, 2020.11.17.20233312. https://doi.org/10.1101/2020.11.17.20233312

Malikov, K., Huang, Q., Shi, S., Stall, N. M., Tuite, A. R., \& Hillmer, M. P. (2021). Temporal Associations between Community Incidence of COVID-19 and Nursing Home Outbreaks in Ontario, Canada. Journal of the American Medical Directors Association, 22(2), 260-262. https://doi.org/10.1016/j. jamda.2020.12.011

Marrocco, F. N., Coke, A., \& Kitts, J. (2020, October 23). Ontario's long-term care COVID-19 commission. First interim recommendations. http://www.ltccommission-commissionsld.ca/ir/pdf/20201023_First_Interim_Letter_ English.pdf 
McArthur, C., Saari, M., Heckman, G. A., Wellens, N., Weir, J., Hebert, P., Turcotte, L., Jbilou, J., \& Hirdes, J. P. (2021). Evaluating the effect of COVID-19 pandemic lockdown on long-term care residents' mental health: A data-driven approach in New Brunswick. Journal of the American Medical Directors Association, 22(1), 187-192. https://doi.org/10.1016/j.jamda.2020.10.028

McGarry, B. E., SteelFisher, G. K., Grabowski, D. C., \& Barnett, M. L. (2020). COVID-19 test result turnaround time for residents and staff in US nursing homes. JAMA Internal Medicine. https://doi.org/10.1001/jamaint ernmed.2020.7330

McMichael, T. M., Currie, D. W., Clark, S., Pogosjans, S., Kay, M., Schwartz, N. G., Lewis, J., Baer, A., Kawakami, V., Lukoff, M. D., Ferro, J., Brostrom-Smith, C., Rea, T. D., Sayre, M. R., Riedo, F. X., Russell, D., Hiatt, B., Montgomery, P., Rao, A. K., ... Duchin, J. S. (2020). Epidemiology of Covid-19 in a longterm care facility in King County, Washington. New England Journal of Medicine, 382(21), 2005-2011. https://doi.org/10.1056/NEJMoa2005412

Ministry of Finance. (2020). Ontario population projections, 2019-2046. Government of Ontario. https://www.fin.gov.on.ca/en/economy/demographics/ projections/

Ministry of Health and Long-Term Care. (2020, September). Capacity planning and analytics division. http://www.ltccommission-commissionsld.ca/presentations/pdf/LTCC_Capacity_Planning_and_Analytics_Overview.pdf

Ministry of Long-Term Care. (2020). Resuming visits in long-term care homes (p. 12). Government of Ontario. http://health.gov.on.ca/en/pro/programs/ltc/ docs/covid-19/mltc_visitor_policy_20200909_en.pdf

Mor, V. (2004). A comprehensive clinical assessment tool to inform policy and practice: Applications of the minimum data set. Medical Care, 42(4), III. https://doi.org/10.1097/01.mlr.0000120104.01232.5e

National Institute for Ageing. (2020). Bringing long-term care home. https://static1. squarespace.com/static/5c2fa7b03917eed $9 \mathrm{~b} 5 \mathrm{a} 436 \mathrm{~d} 8 / \mathrm{t} / 5 \mathrm{fb} 57 \mathrm{afdbb} 4 \mathrm{de}-$ c698ea3b7d2/1605729021992/BringLTCHome_V2.11.17\%284\%29pdf. pdf

Ng, R., Lane, N., Tanuseputro, P., Mojaverian, N., Talarico, R., Wodchis, W. P., Bronskill, S. E., \& Hsu, A. T. (2020). Increasing complexity of new nursing home residents in Ontario, Canada: A serial cross-sectional study. Journal of the American Geriatrics Society, 68(6), 1293-1300. https://doi. org/10.1111/jgs.16394

Ontario Agency for Health Protection and Promotion, Provincial Infectious Diseases Advisory Committee, Ontario, \& Public Health Ontario. (2012). 
Best practices for infection prevention and control programs in Ontario: In all health care settings. Public Health Ontario. https://www.deslibris.ca/ ID/236594

Ontario Long-Term Care Association. (2020). The role of long-term care. Oltca. Com. https://www.oltca.com/oltca/OLTCA/Public/LongTermCare/Facts Figures.aspx

Government of Ontario. (2020, April 22). Ontario takes immediate steps to further protect long-term care residents and staff during COVID-19 outbreak. Ontario.Ca. https://news.ontario.ca/en/release/56737/ontario-takes-immedi ate-steps-to-further-protect-long-term-care-residents-and-staff-duringcovid-19

Ouslander, J. G., \& Grabowski, D. C. (2020). COVID-19 in nursing homes: Calming the perfect storm. Journal of the American Geriatrics Society, 68(10), 2153-2162. https://doi.org/10.1111/jgs.16784

Postill, G., Murray, R., Wilton, A. S., Wells, R. A., Sirbu, R., Daley, M. J., \& Rosella, L. C. (2020). An analysis of mortality in Ontario using cremation data: Rise in cremations during the COVID-19 pandemic. MedRxiv. https://doi. org/10.1101/2020.07.22.20159913

Public Health Agency of Canada. (2020). From risktoresilience: Anequityapproach to COVID-19. https://www.canada.ca/content/dam/phac-aspc/documents/ corporate/publications/chief-public-health-officer-reports-state-pub lic-health-canada/from-risk-resilience-equity-approach-covid-19/cphocovid-report-eng.pdf

Public Health Ontario. (2020a). Enhanced Epidemiological Summary: Trends of COVID-19 Incidence in Ontario (p. 18). Ontario Agency for Health Protection and Promotion. https://www.publichealthontario.ca/-/media/doc uments/ncov/epi/covid-19-epi-trends-incidence-ontario.pdf?la=en

Public Health Ontario. (2020b). Median influenza immunization coverage rates: Ontario hospital and long-term care staff, 2019-20 influenza season (p. 2). Ontario Agency for Health Protection and Promotion. https://www.publi chealthontario.ca/-/media/documents/f/2020/factsheet-influenza-immu nization-rates-hcw-2019-20.pdf?la=en

RNAO. (2020). Reuniting family with their loved ones in long-term care homes during COVID-19. Registered Nurses' Association of Ontario. https://rnao. ca/sites/rnao-ca/files/FINAL_RNAO_Statement_on_Reuniting_Families_in_LTC_1.pdf

Rios, P., Radhakrishnan, A., Williams, C., Ramkissoon, N., Pham, B., Cormack, G. V., Grossman, M. R., Muller, M. P., Straus, S. E., \& Tricco, A. C. (2020). 
Preventing the transmission of COVID-19 and other coronaviruses in older adults aged 60 years and above living in long-term care: A rapid review. Systematic Reviews, 9(1), 218. https://doi.org/10.1186/s13643-020-01486-4

Rochon, P. A. (2007). Variation in nursing home antipsychotic prescribing rates. Archives of Internal Medicine, 167(7), 676. https://doi.org/10.1001/ archinte.167.7.676

Rochon, P. A., Wu, W., Giannakeas, V., \& Stall, N. M. (2020). The missing pieces of the COVID-19 puzzle. Journal of the American Geriatrics Society. https:// doi.org/10.1111/jgs.16646

Royal Society of Canada. (2020). Restoring trust: COVID-19 and the future of longterm care. https://rsc-src.ca/sites/default/files/LTC\%20PB\%20\%2B\%20ES_ EN_0.pdf

Schlaudecker, J. D. (2020). Essential family caregivers in long-term care during the COVID-19 pandemic. Journal of the American Medical Directors Association, 21(7), 983. https://doi.org/10.1016/j.jamda.2020.05.027

Sepulveda, E. R., Stall, N. M., \& Sinha, S. K. (2020). A comparison of COVID-19 mortality rates among long-term care residents in 12 OECD countries. Journal of the American Medical Directors Association, 21(11), 1572-1574. e3. https://doi.org/10.1016/j.jamda.2020.08.039

Shen, K. (2020). Relationship between nursing home COVID-19 outbreaks and staff neighborhood characteristics. MedRxiv, 2020.09.10.20192203. https:// doi.org/10.1101/2020.09.10.20192203

Stall, N. M., Farquharson, C., Fan-Lun, C., Wiesenfeld, L., Loftus, C. A., Kain, D., Johnstone, J., McCreight, L., Goldman, R. D., \& Mahtani, R. (2020). A hospital partnership with a nursing home experiencing a COVID-19 outbreak: Description of a multiphase emergency response in Toronto, Canada. Journal of the American Geriatrics Society, 68(7), 1376-1381. https:// doi.org/10.1111/jgs.16625

Stall, N. M., Fischer, H. D., Fung, K., Giannakeas, V., Bronskill, S. E., Austin, P. C., Matlow, J. N., Quinn, K. L., Mitchell, S. L., Bell, C. M., \& Rochon, P. A. (2019). Sex-specific differences in end-of-life burdensome interventions and antibiotic therapy in nursing home residents with advanced dementia. JAMA Network Open, 2(8), e199557. https://doi.org/10.1001/jamanet workopen.2019.9557

Stall, N. M., Johnstone, J., McGeer, A. J., Dhuper, M., Dunning, J., \& Sinha, S. K. (2020). Finding the right balance: An evidence-informed guidance document to support the re-opening of canadian nursing homes to family care- 
givers and visitors during the coronavirus disease 2019 pandemic. Journal of the American Medical Directors Association, 21(10), 1365-1370.e7. https://doi.org/10.1016/j.jamda.2020.07.038

Stall, N. M., Jones, A., Brown, K. A., Rochon, P. A., \& Costa, A. P. (2020). For-profit long-term care homes and the risk of COVID-19 outbreaks and resident deaths. CMAJ, 192(33), E946-E955. https://doi.org/10.1503/cmaj.201197

Stall, N. M., Wu, W., Lapointe-Shaw, L., Fisman, D. N., Giannakeas, V., Hillmer, M. P., \& Rochon, P. A. (2020). Sex- and age-specific differences in COVID-19 testing, cases, and outcomes: A population-wide study in Ontario, Canada. Journal of the American Geriatrics Society, 68(10), 2188-2191. https://doi. org/10.1111/jgs.16761

Stall, N. M., Zipursky, J. S., Rangrej, J., Jones, A., Costa, A. P., Hillmer, M. P., \& Brown, K. (2020). Increased prescribing of psychotropic medications to Ontario nursing home residents during the COVID-19 pandemic. MedRxiv, 2020.11.26.20239525. https://doi.org/10.1101/2020.11.26.20239525

Stall, N. M., Zipursky, J. S., Rangrej, J., Jones, A., Costa, A. P., Hillmer, M. P., \& Brown, K. (2021). Assessment of Psychotropic Drug Prescribing Among Nursing Home Residents in Ontario, Canada, During the COVID-19 Pandemic. JAMA Internal Medicine, 181(6), 861-863. https://doi.org/10.1001/ jamainternmed.2021.0224

Suarez-Gonzalez, A. (2020). Detrimental effects of confinement and isolation on the cognitive and psychological health of people living with dementia during COVID-19: Emerging evidence. International Long Term Care Policy Network.

Sundaram, M. E., Calzavara, A., Mishra, S., Kustra, R., Chan, A. K., Hamilton, M. A., Djebli, M., Rosella, L. C., Watson, T., Chen, H., Chen, B., Baral, S. D., \& Kwong, J. C. (2020). The individual and social determinants of COVID-19 in Ontario, Canada: A population-wide study. MedRxiv, 2020.11.09.20223792. https://doi.org/10.1101/2020.11.09.20223792

Tanuseputro, P., Chalifoux, M., Bennett, C., Gruneir, A., Bronskill, S. E., Walker, P., \& Manuel, D. (2015). Hospitalization and mortality rates in long-term care facilities: Does for-profit status matter? Journal of the American Medical Directors Association, 16(10), 874-883. https://doi.org/10.1016/j.jam da.2015.06.004

The National Collaborating Centre for Methods and Tools. (2020). Rapid Review: What risk factors are associated with COVID-19 outbreaks and mortality in long-term care facilities and what strategies mitigate risk? McMaster University. https://www.nccmt.ca/uploads/media/media/0001/02/3021cb- 
8ca67e86dfa1d29ea5ef2ea14dc486bfe1.pdf

Tupper, S. M., Ward, H., \& Parmar, J. (2020). Family Presence in Long-Term Care During the COVID-19 Pandemic: Call to Action for Policy, Practice, and Research. Canadian Geriatrics Journal, 23(4), 335-339. https://doi. org/10.5770/cgj.23.476

Van der Roest, H. G., Prins, M., van der Velden, C., Steinmetz, S., Stolte, E., van Tilburg, T. G., \& de Vries, D. H. (2020). The Impact of COVID-19 Measures on Well-Being of Older Long-Term Care Facility Residents in the Netherlands. Journal of the American Medical Directors Association, 21(11), 1569-1570. https://doi.org/10.1016/j.jamda.2020.09.007

Verbeek, H., Gerritsen, D. L., Backhaus, R., de Boer, B. S., Koopmans, R. T. C. M., \& Hamers, J. P. H. (2020). Allowing visitors back in the nursing home during the COVID-19 crisis: A dutch national study into first experiences and impact on well-being. Journal of the American Medical Directors Association, 21(7), 900-904. https://doi.org/10.1016/j.jamda.2020.06.020

Vijh, R., Ghafari, C., Hayden, A., Schwandt, M., Sekirov, I., Morshed, M., Levett, P., Krajden, M., Boraston, S., Daly, P., Lysyshyn, M., Harding, J., McLennan, M., Chahil, N., Mak, A., \& McKee, G. (2020). Serological survey following SARS-COV-2 outbreaks at long-term care facilities in metro Vancouver, British Columbia: Implications for outbreak management and infection control policies. American Journal of Infection Control, 0(0). https://doi. org/10.1016/j.ajic.2020.10.009

Volpp, K. G., Loewenstein, G., \& Buttenheim, A. M. (2021). Behaviorally informed strategies for a national COVID-19 vaccine promotion program. JAMA, 325(2), 125-126. https://doi.org/10.1001/jama.2020.24036

White, E. M., Kosar, C. M., Feifer, R. A., Blackman, C., Gravenstein, S., Ouslander, J., \& Mor, V. (2020). Variation in SARS-CoV-2 prevalence in U.S. skilled nursing facilities. Journal of the American Geriatrics Society, 68(10), 21672173. https://doi.org/10.1111/jgs.16752 